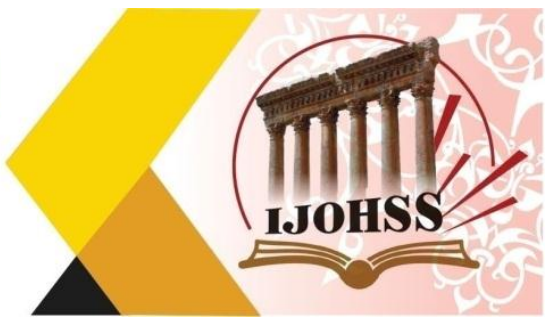

\title{
المتطلبات الوظيفية لملابس العمال في المملكة العربية السعودية
}

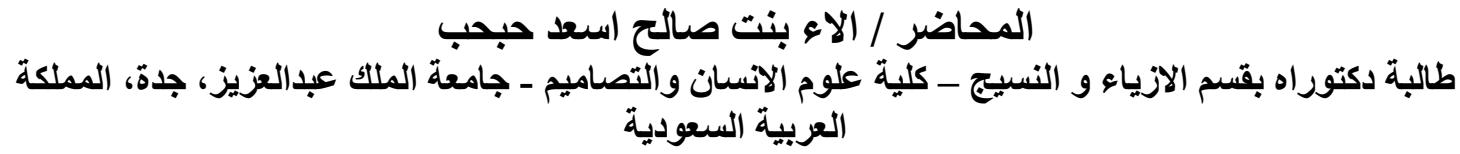

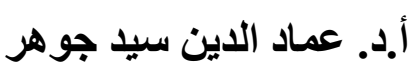

أستاذ بقسم الأزياء والنسيج، كلية علوم الانسان والتصاميم، جامعة الملك عبد العزيز، جدة، المبل المملكة العربية

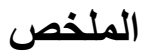

تعتبر صناعة الملابس الجاهزة في المملكة العربية السعودية من الصناعات التي تتمو بشكل ملحوظ وتحتاج الى دعم كبير حتى يكتمل نمو ها على أساس سليم ، وهذا يتطلب وضع استر اتيجيات على اسس علمية و التكنولوجية لتطوير صناعة الملابس داخل المملكة مما يؤدي الى سد احتباجات السوق المحلي من الملابس الجاهزة وتقليل المنتجات الملبسية المستوردة من الخارج ، وبذلك يعمل على بناء الاقتصاد الوطني وتحقيق اهداف التنمية

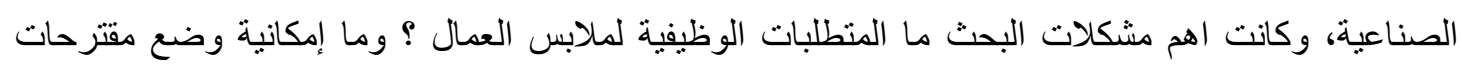
تصميمية تتلاءم مع طبيعة العمل وتحقق رغبات العمال ؟ ويهدف البحث الى تحديد المتطلبات الوظيفية لملابس العمال ، و إمكانية وضع مقترحات تصميمية تتلاءم مع طبيعة العمل وتحقق رغبات العمال ، وترجع اهمية البحث الاسهام في طرح المقترحات والتوصيات المناسبة للارتقاء بملابس العمال مما يحقق انتاج افضل ، مساعدة أصحاب المصانع و العملاء في تحسين اختيار تصاميم العمال بما يتناسب مع طبيعة العمل ، محاولة تطوير وتحسين الكفاءة الإنتاجية لقطاع الملابس والنسيج بالمملكة العربية السعودية تمانشياً مع رؤية المملكة 2030 ( اقتصاد مزدهر ) ، ومن نتائج البحث نوجد فروق ذات دلالة احصائية بين التصاميم المقترحة لملابس ونس

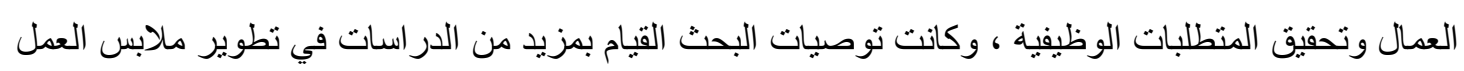

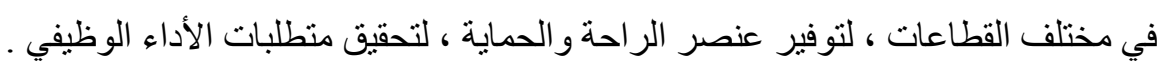
الكلمات المفتاحية: المتطلبات الوظيفية، ملابس العمال. 


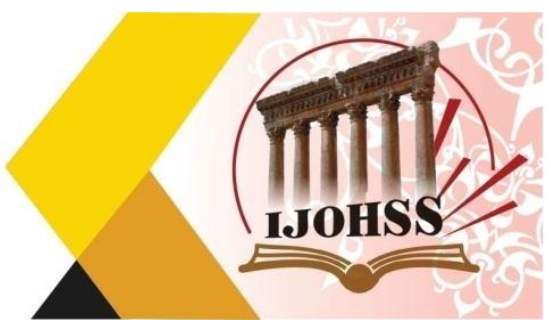

\title{
Functional Requirements for work's Uniform in the Kingdom of Saudi Arabia
}

\author{
Alaa Saleh Asaad Habhab \\ PhD student, Department of Clothing and Textiles - of Human Sciences and Designs - \\ King Abdulaziz University in Jeddah - Kingdom of Saudi Arabia \\ Prof. Dr. Emad El-Din Sayed Gohar \\ Professor in Clothing and Textiles Department, Faculty of Human Sciences And \\ Designs, King Abdulaziz University, Jeddah, Saudi Arabia
}

\begin{abstract}
The ready-made garments industry in the Kingdom of Saudi Arabia is developing and growing, and therefore it needs great support and requirements in order to complete its growth using the main basic techniques،This requires a conscious strategy based on the science and technology to develop the garment industry in the Kingdom, which leads to cover the needs of the local market for ready-made garments instead of import, and in this case, the garment industry can support the national economy and achieve the industrial development goals. The main important research problems What are the functional requirements for work's uniform? What is the possibility to develop the suggested designs that are suitable with the work environment and fulfill the comfort of workers? The research aims to determine the functional requirements of work's uniform, and the possibility of developing the suggested designs which suitable the work environment and fulfill the comfort of workers .The importance of the research is to contribute the appropriate recommendations to improve work's uniform, which and achieve high mass production and help the owners of factories and customers to improve the selection of workers' designs during the production according to the environment of work. Also to develop and improve the efficiency of production of the apparel and textile sector in the Kingdom of Saudi Arabia in line with the Kingdom's vision 2030 (Successfully Economy).

The results of the research show that there are statistically significant differences between the suggested designs for workers' uniform and the fulfillment of functional requirements. One of the most important recommendations of the research is to carry out more studies to develop the workers' uniforms in various sectors, to achieve the comfort, protection, the requirements of performance .
\end{abstract}

Keywords: Functional requirements, work's ${ }^{\text {s }}$ uniform. 
العداد (30) مبراير 2022

Volume (30) February 2022

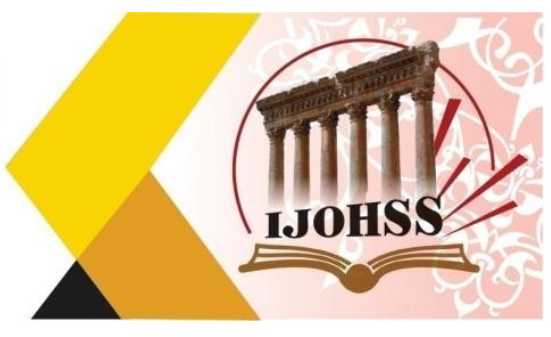

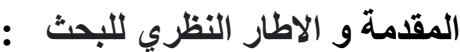

في ظل المتغيرات الاقتصادية العالمية يجب المارية على المؤسسات الصغيرة التي تقوم بإنتاج الملابس الجاهزة

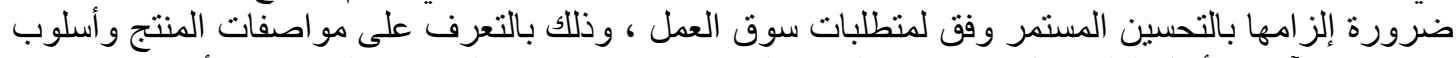

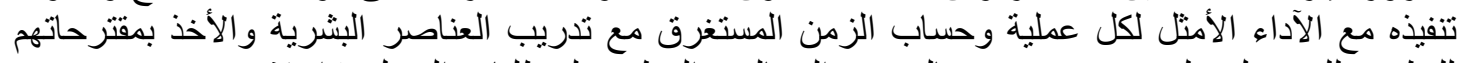
للتطوير للحصول على منتج جيد يفي بالغرض الجية الجمالي و الوظيفي لمتطلبات العميل ( اسلام حسين ، 2011 ،

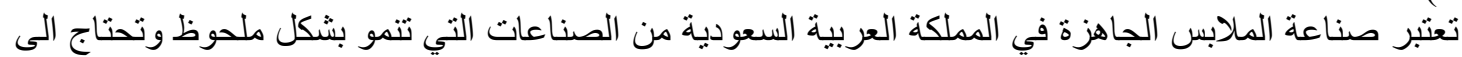

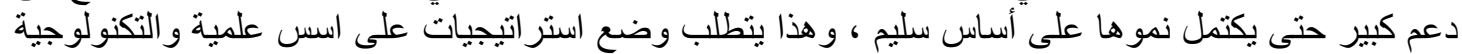

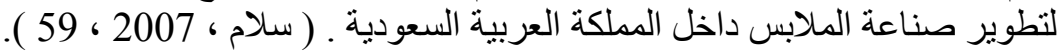

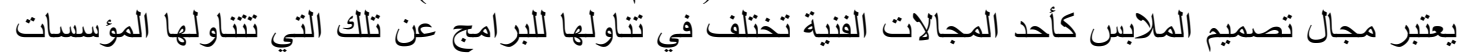

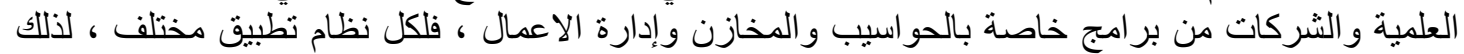

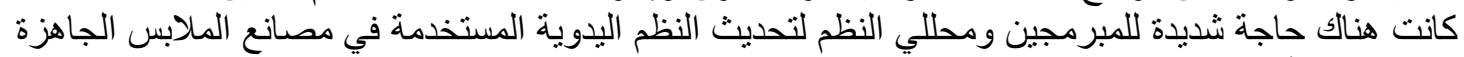

وتزويدها بالأنظمة التطبيقية لما في ذلك من اثر بالغ في تطوير العمل وتقدمه ( فاضل ، 2006 ، 1 ـ ).

تؤدي الملابس التي نرتديها دور ا حيويا في حياتتا وتمكن الآخرين من الحكم الأولى على القطعة الملبسية المناسبة

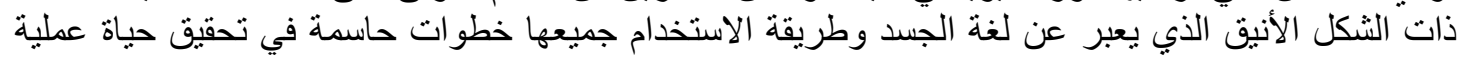

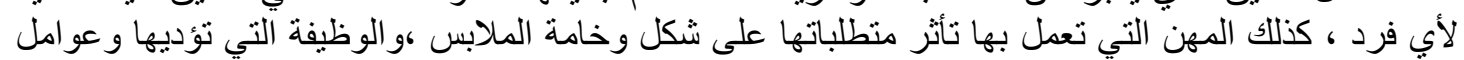

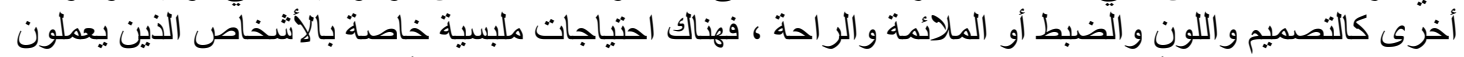

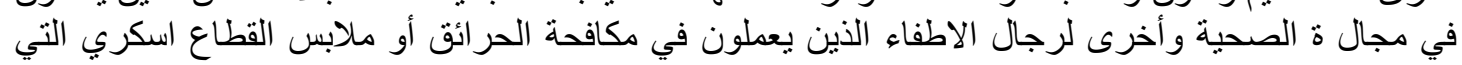

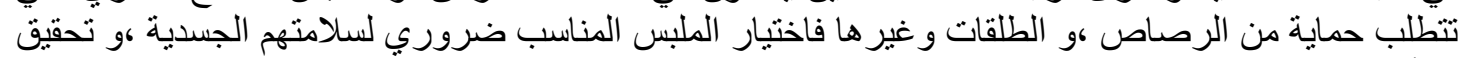

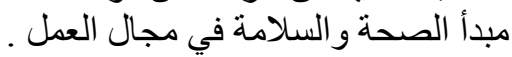

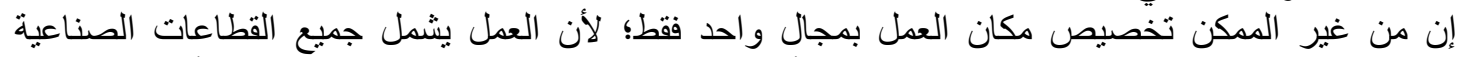

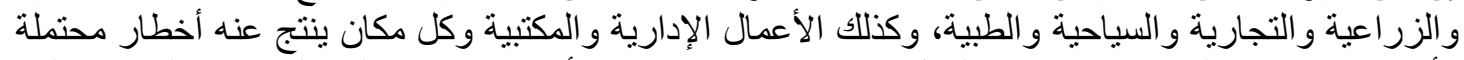

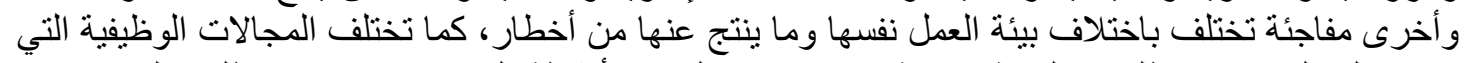

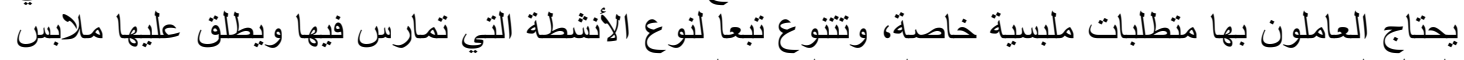

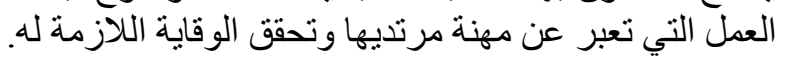

إن مجال الملابس الوظيفية مجال واسع ومتنوع بتنوع الوظائف التي نعمل بها ، حيث أن لكل مهنة مواصفاتها

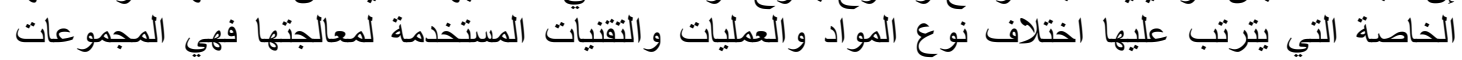

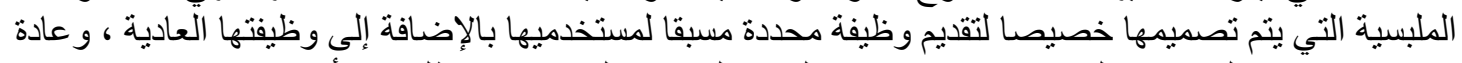

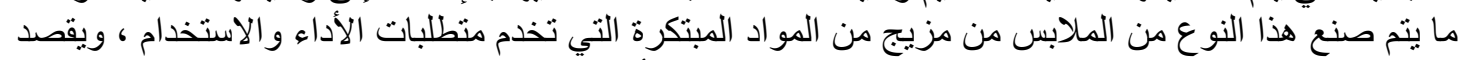

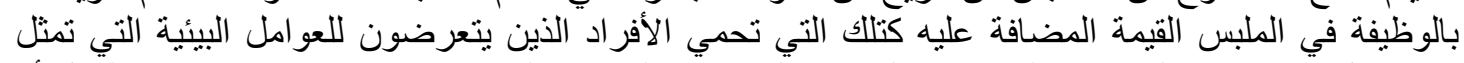

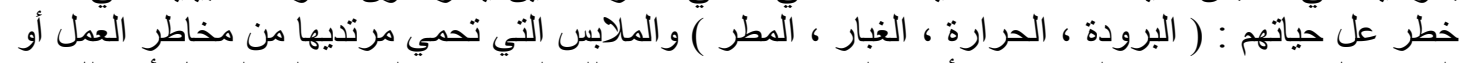

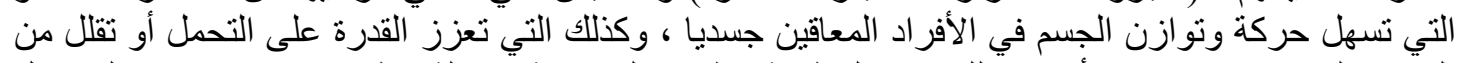

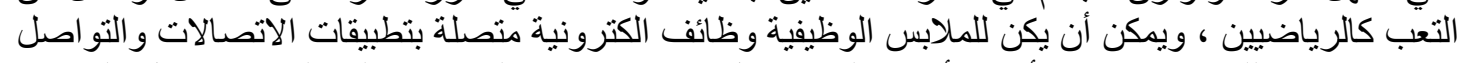

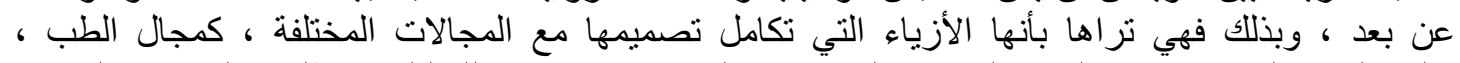

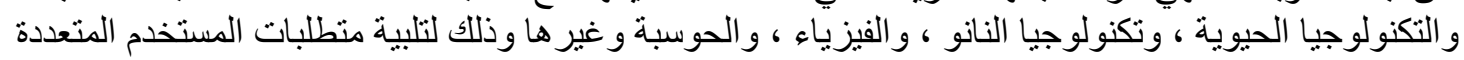

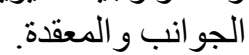
وتعرف الملابس الوظيفة التية بأنها قيمة جيدة التصميم ير اعى فيها حرية الحركة لمرتديها كما تراعي معايير

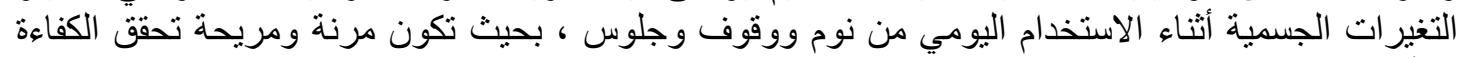

و الأمن ضد المخاطر ( السليماني ، 2021 ، 74 ) . 
العدد (30)

Volume (30) February 2022

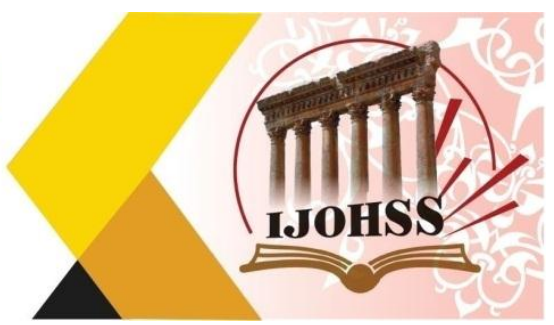

أما (وفاء سماحة ، 2017 ، 75) فتعرف الملابس الوظيفية بأنها قيمة جيدة التصميم ير اعى فيها حرية الحركة

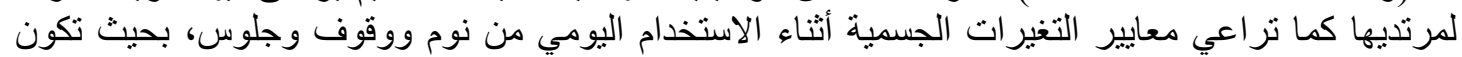

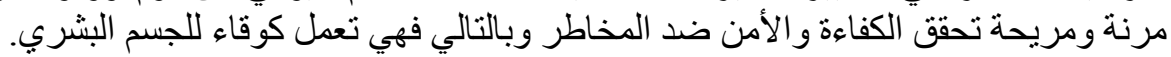

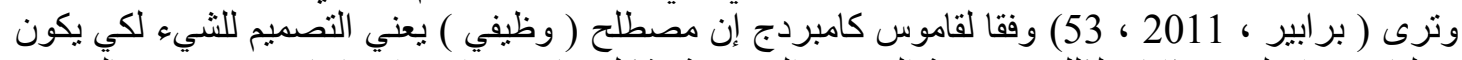

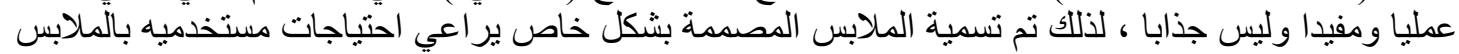

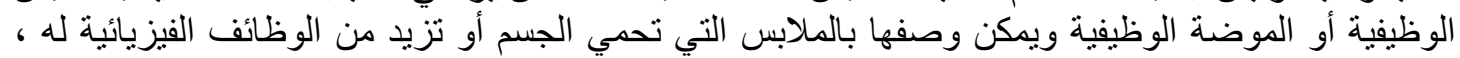

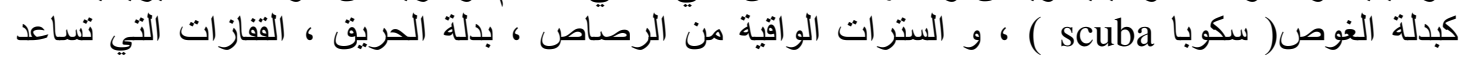

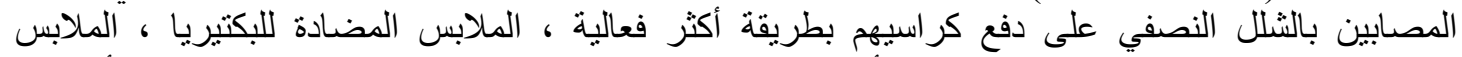

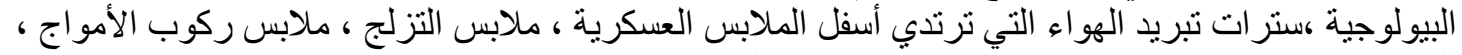

الملابس المقاومة لبرودة الطقس ، وملابس السباحة ( السليماني ، 2021 ، 74 ) .

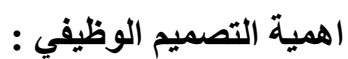

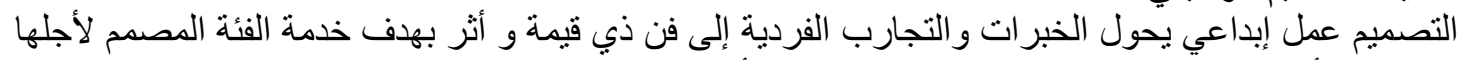

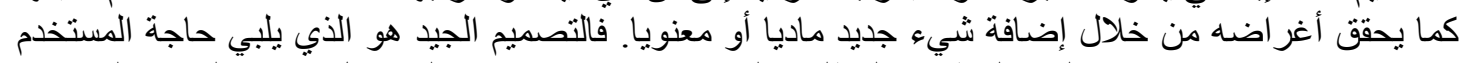

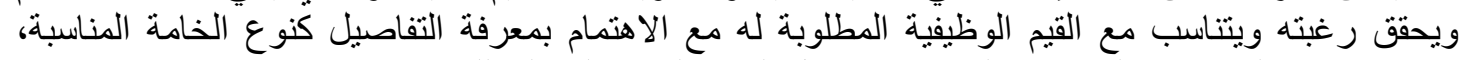

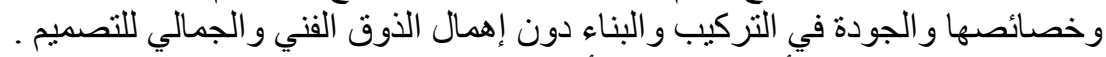

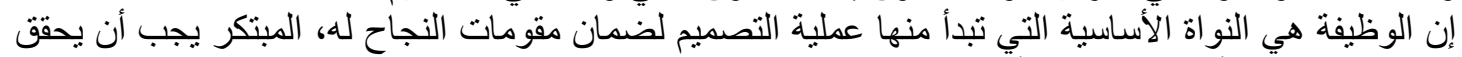

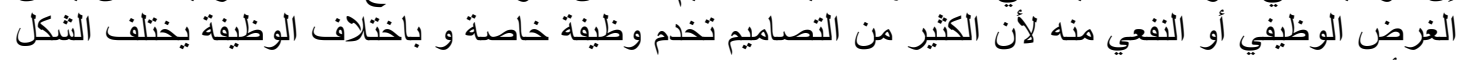

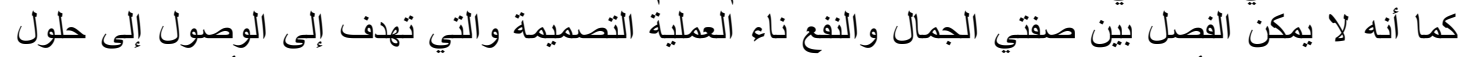

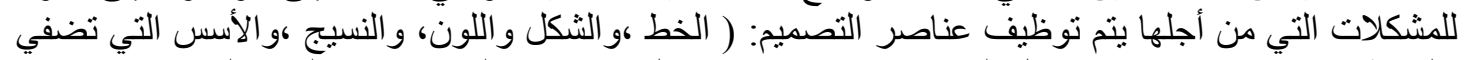

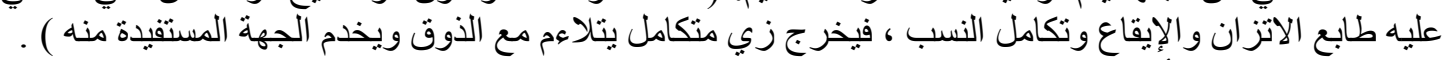

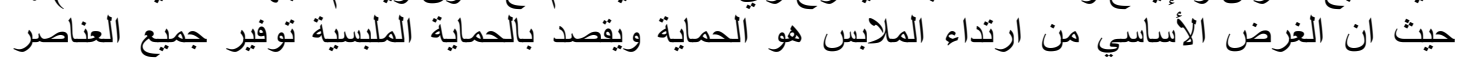

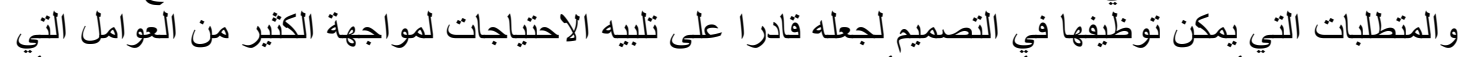

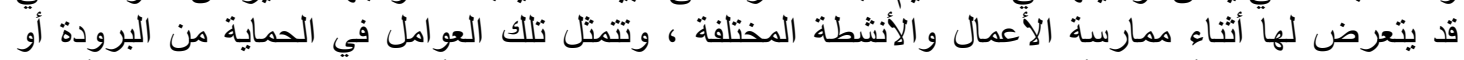

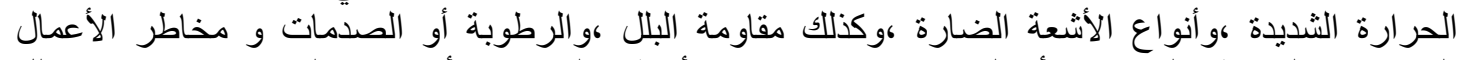

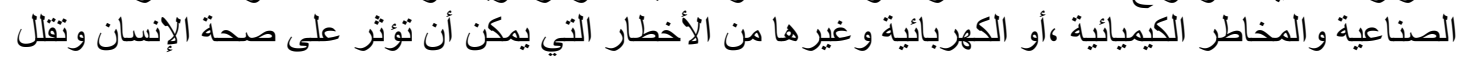
من إنتاجيته .

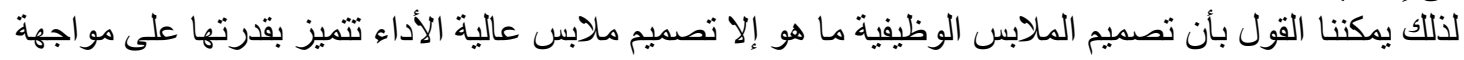

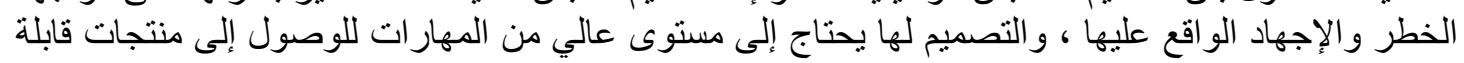

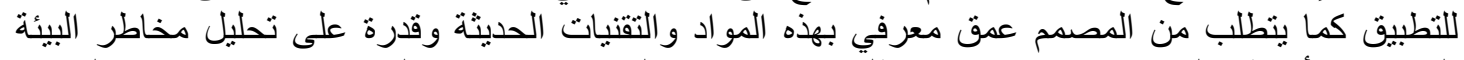

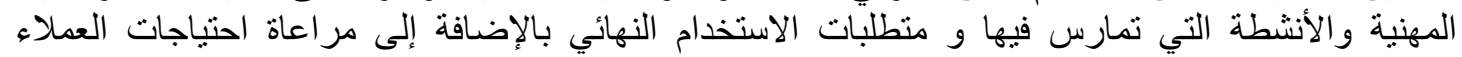
و وتفضيلاتهم

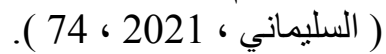

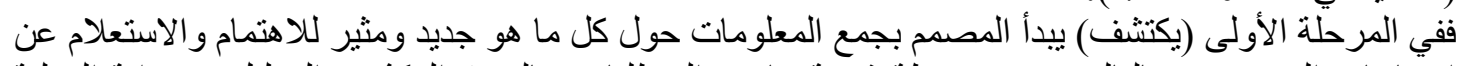

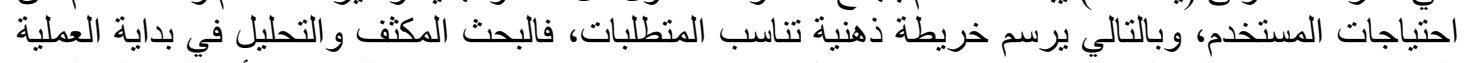

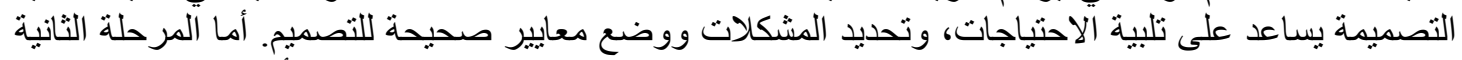

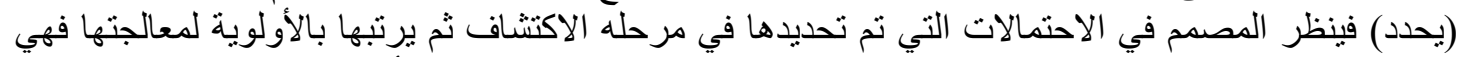

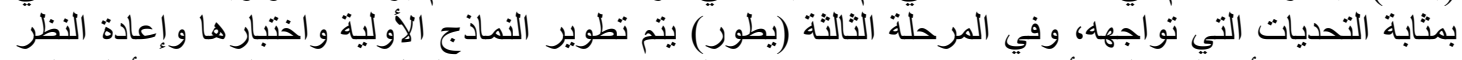

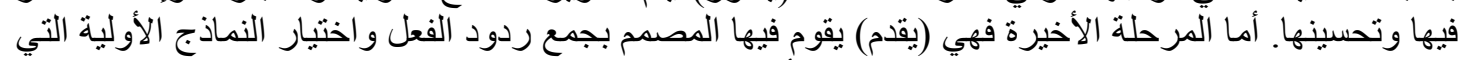

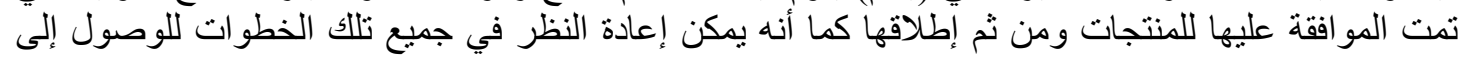




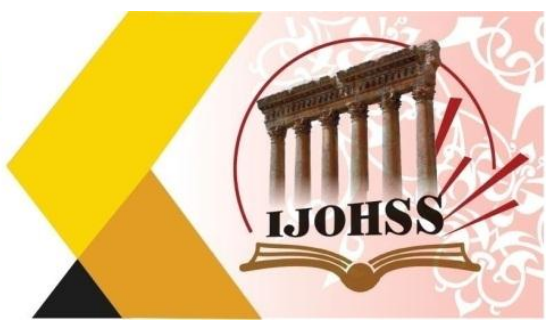

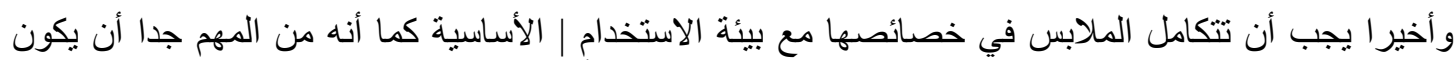

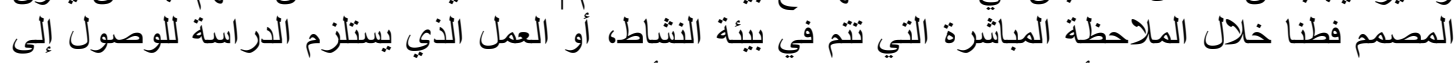

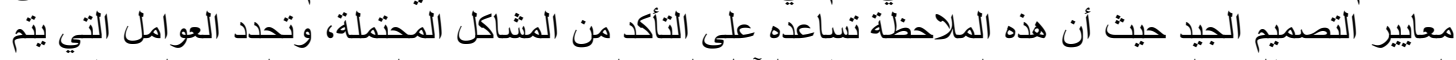
التصميم في ظلاها كالقيود في حركه الجسم - مناطق التآكل المحتملة ـ الاعتبار ات التهن المناخية و البيئية و المخاطر.

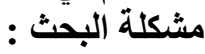
تعتبر مشكلة البحث هي المحور الاساسي التي يينى عليها اهداف البحث وفروضها يمكن عرض المشكلة في

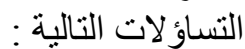
1- ما ما المتطلبات الوظية : مالبية لملابس العمال ؟ 2- - ما إمكانية وضع مقترحات تصميمية تتلائم مع طبيعة العمل وتحقق رغبات العمال العمال ؟

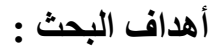

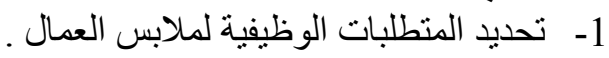

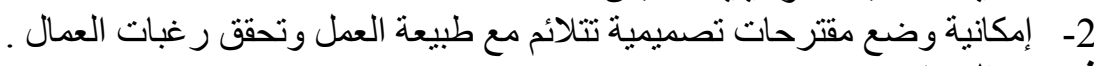

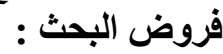

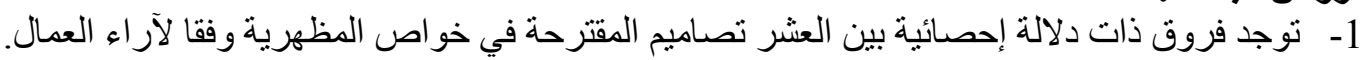

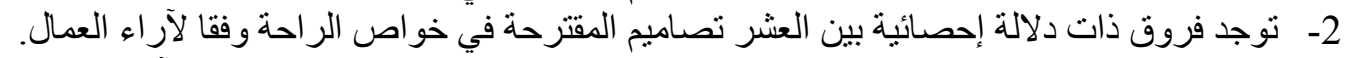

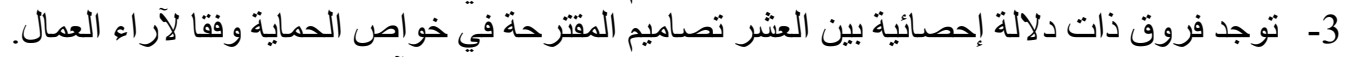
4- توجد فروق ذات دلالة احصائية بين التصاميم العشر المقترحة وفقا لآر اء العمال .

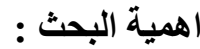

1- الاسهام في طر ح المقترحات و التوصيات المناسبة للارتقاء بملابس العمال مما يحقق انتاج افضل .

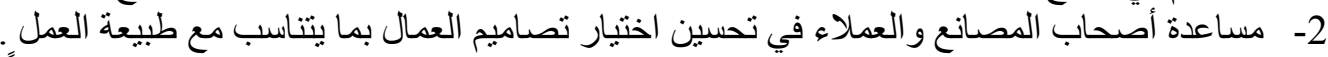

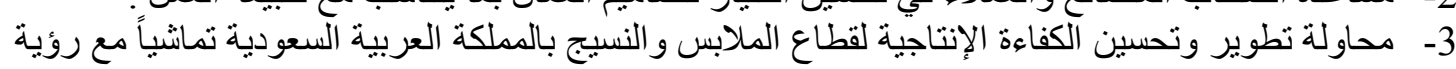

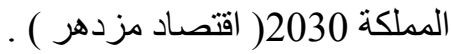
منهج البحث : اتبع البحثث المنهج الوصفي من خلال الدر اسة التحليلية والدر اسة التطبيقية من خلال تصميم زي للعمال.

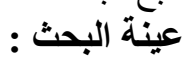
عدد 50 من العمال العاملين في مجال البناء.

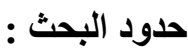

شملت حدود البحث على عمال من مؤسسة المشارق للتجارة و المقاو لات العامة بمكة المكرمة و عمال من مؤسسة

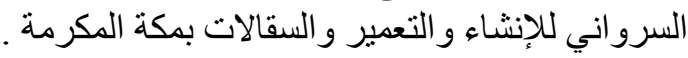

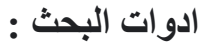

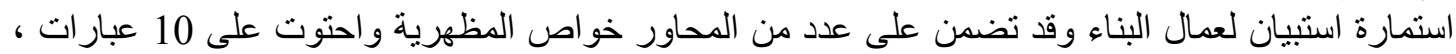

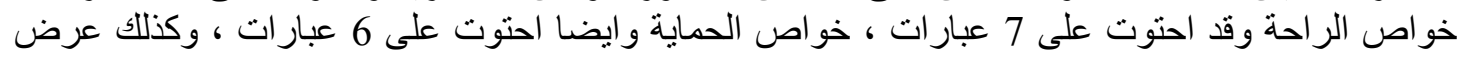

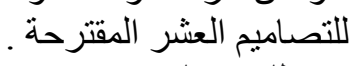

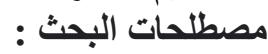

Functional Requirements المتطلبات الوظيفية:

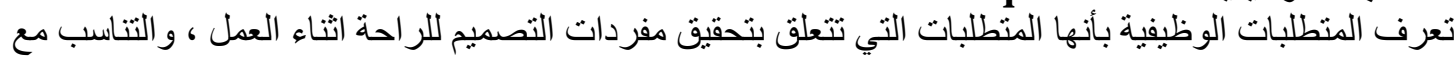
الاداء الحركي المطلوب ، وتو افر الامان وسهولة الاستخدام من حيث الارنداء و الخلع ومناسبة الخامة للنشاط من

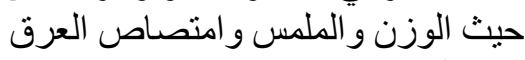

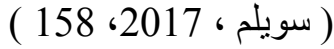
ملابس العمال (Apparel of Workers) : ملفي (158)

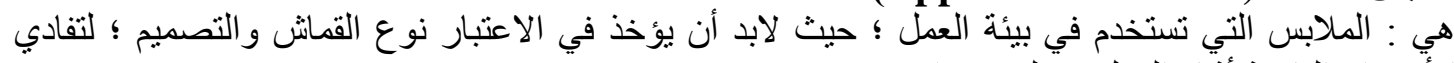
الأضرار الناتجة أثناء العمل ( دبليو، هوارد رييس ، 
المبلة اللحولية اللملوم الآنسانية والامتياعية International Journal on Humanities and Social Sciences website:www.ijohss.com Email:editor@ijohss.com العدد (30) فبراير 2022 ISSN: $2415-4822$ Volume (30) February 2022

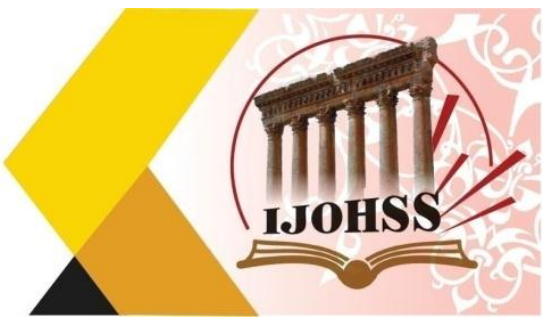

الاطار التطبيقي للبحث :

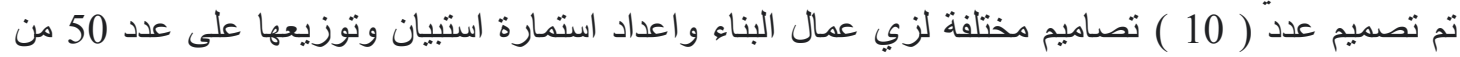
العمال لقياس الفروض المطلوبة في البحث . تصني

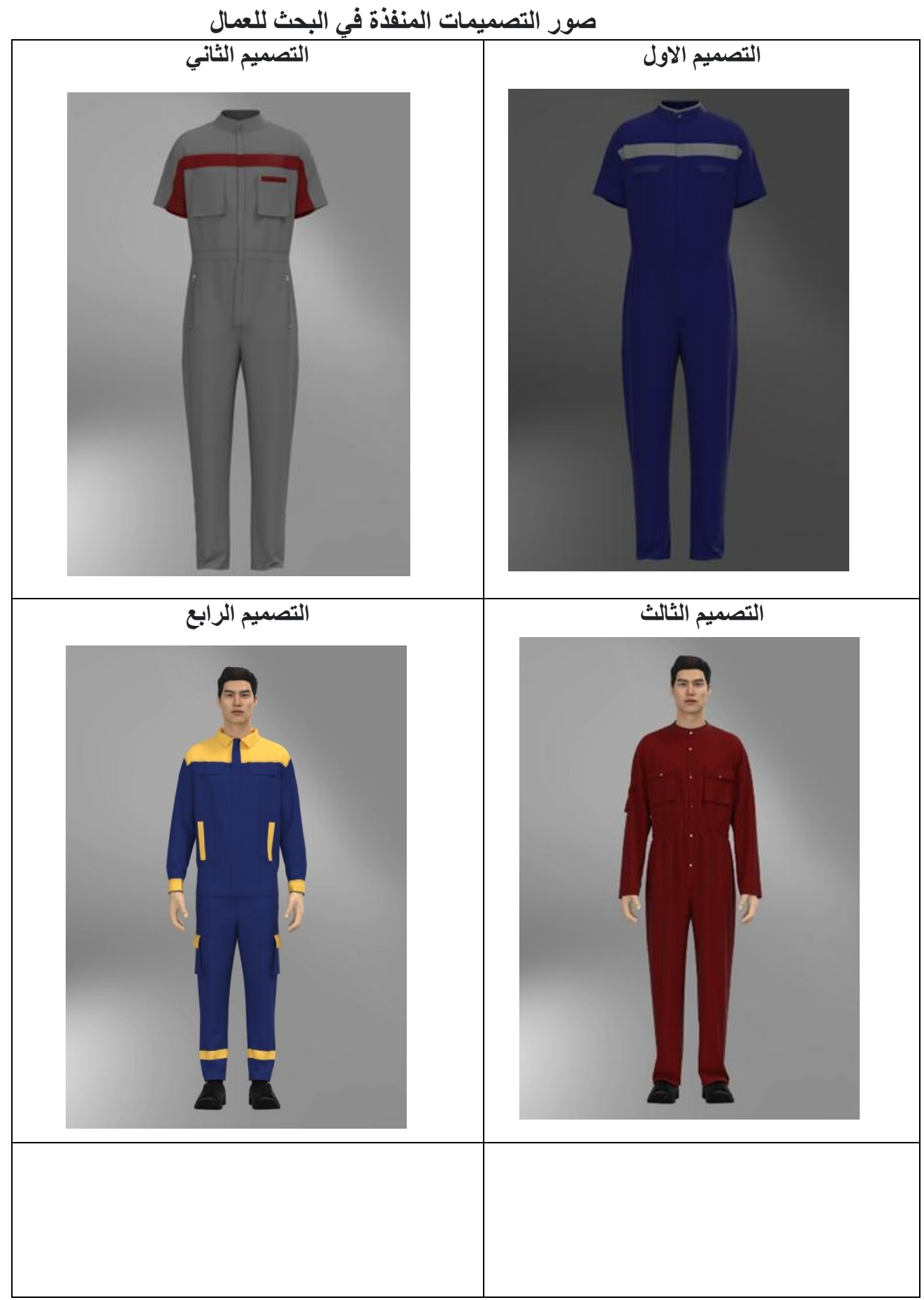


المجلة المولية اللملوم الآنسانية والامتماعية International Journal on Humanities and Social Sciences website:www.ijohss.com Email:editor@ijohss.com العدد (30) فبراير 2022 ISSN: $2415-4822$
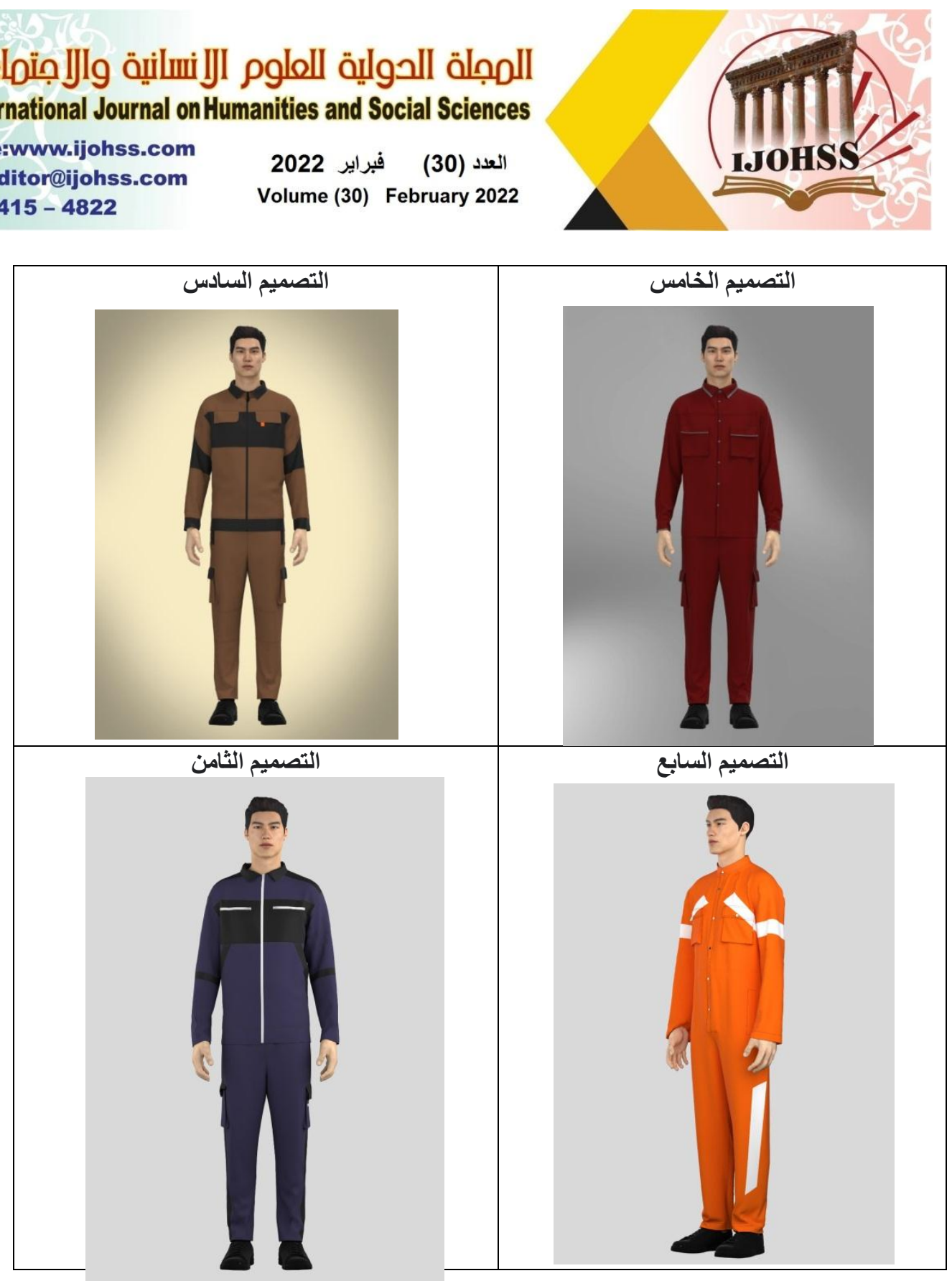
المجلة المولية اللملوم الآنسانية والامتماعية International Journal on Humanities and Social Sciences website:www.ijohss.com Email:editor@ijohss.com العدد (30) فبراير 2022 ISSN: 2415 - 4822 Volume (30) February 2022
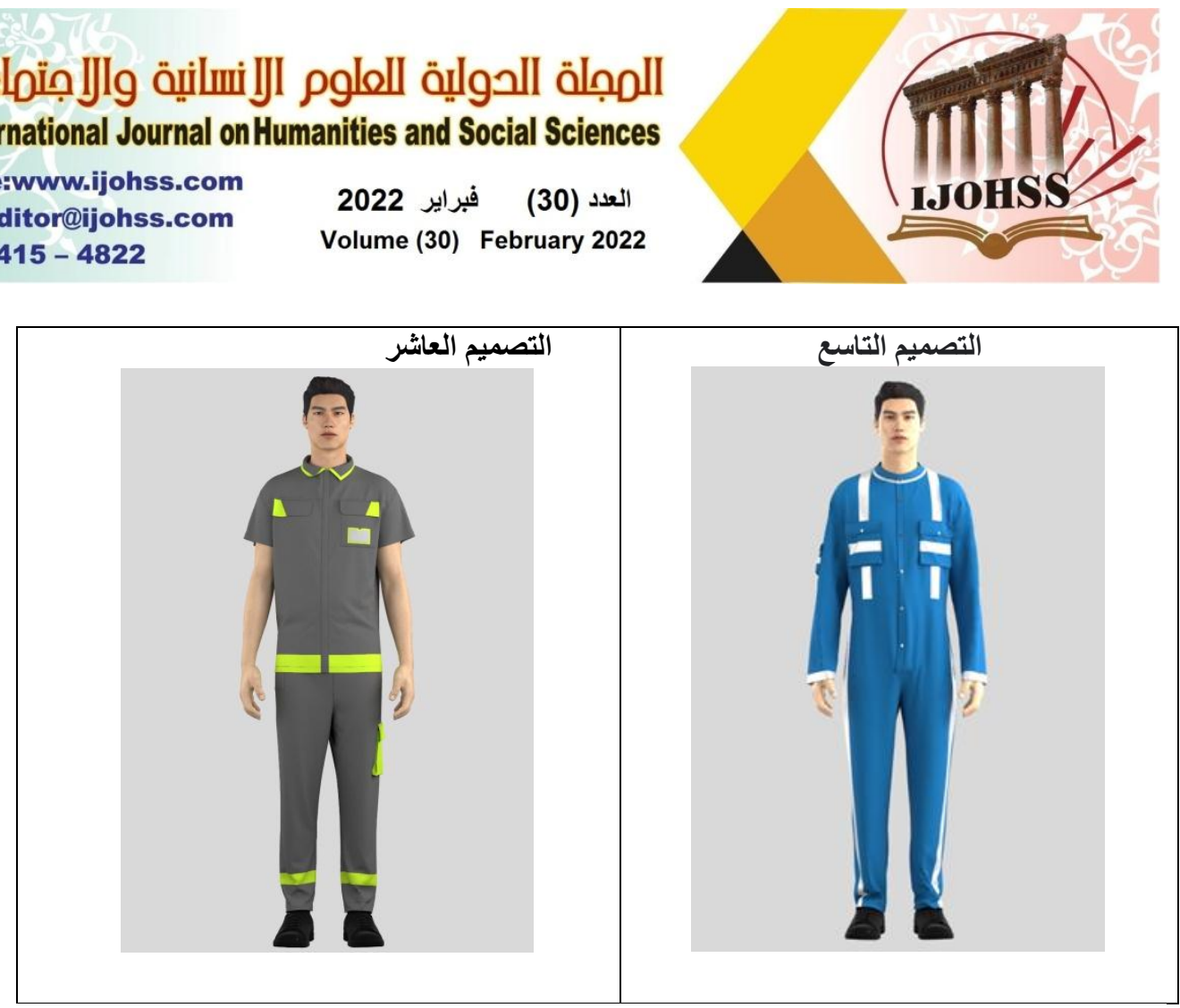

صدق وثبات استبانة البحث :

استبيان تقييم العمال للتصميمات المقترحة :

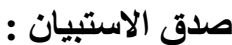
هو قدرة الاستبيان على قياس ما وضع لقياسه . صدق الاتساق الاخلي : الأني 1- حساب معامل الارتباط بين درجة كل عبارة من العبارات المكونة لكل محور ، و الدرجة الكلية للمحور

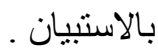
2- حساب معامل الارتباط بين الدرجة الكلية لكل محور من محاور الاستبيان و الدرجة الكلية بالاستبيان .

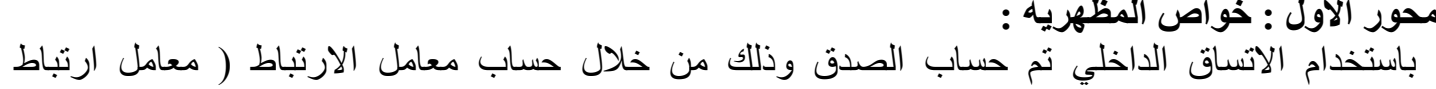

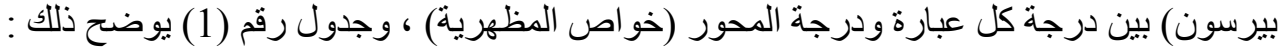

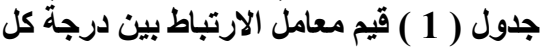

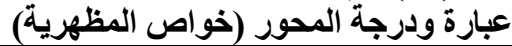

\begin{tabular}{|c|c|c|}
\hline الدلالة & الارتباط & p \\
\hline 0.01 & 0.829 & -1 \\
\hline 0.01 & 0.905 & -2 \\
\hline 0.01 & 0.714 & -3 \\
\hline 0.01 & 0.888 & -4 \\
\hline 0.05 & 0.640 & -5 \\
\hline 0.01 & 0.808 & -6 \\
\hline 0.01 & 0.946 & -7 \\
\hline 0.01 & 0.753 & -8 \\
\hline 0.05 & 0.611 & -9 \\
\hline 0.05 & $\begin{array}{l}0.639 \\
\end{array}$ & -10 \\
\hline
\end{tabular}




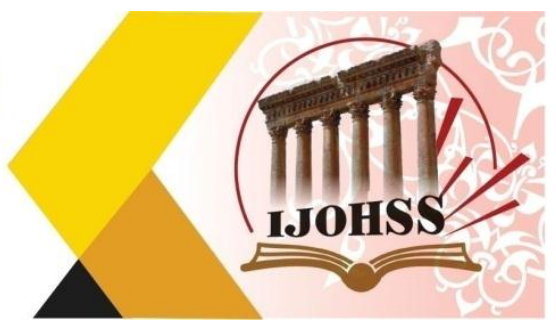

من خلال الجدول السابق نجد أن نتائج معامل الارتباط كلها دالة عند مستوى (0.01 - 0.05) وذلك لاقتر ابها من

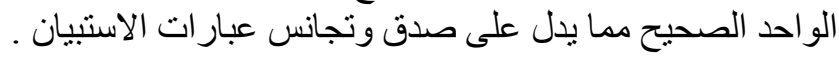

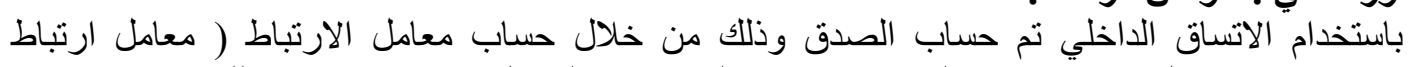
بيرسون) بين درجة كل عبارة ودرجة المحور (خو اص الراحة) ، و والجدول رقم (2 ) يوضح ذللك:

جدول ( 2 ) قيم معامل الارتباط بين درجة كل عبارة ودرجة المحور (خو اصل الراطين درجة الراحة)

\begin{tabular}{|c|c|c|}
\hline الدلالة & الارتباط & p \\
\hline 0.01 & 0.851 & -1 \\
\hline 0.01 & 0.928 & -2 \\
\hline 0.05 & 0.607 & -3 \\
\hline 0.05 & 0.631 & -4 \\
\hline 0.01 & 0.873 & -5 \\
\hline 0.01 & 0.723 & -6 \\
\hline 0.01 & 0.791 & -7 \\
\hline 0.01 & 0.834 & -8 \\
\hline
\end{tabular}

من خلال الجدول السابق نجد أن نتائج معامل الارتباط كلها دالة عند مستوى (0.01 - 0.05) لاقتر ابها من

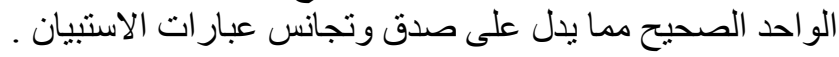
المحور الثالث : خواص الحماية :

باستخدام الاتساق الداخلي تم حساب الصدق وذللك بحساب معامل الارتباط ( معامل ارتباط بيرسون ) بين درجة كل عبارة ودرجة المحور (خو اص الحماية) ، و الجدول رقم ( جدول ( 3 ) قيم معامل الارتباط بين درجة كل عبارة ودرجة المحور (خواص الارب الحماية)

\begin{tabular}{|c|c|c|}
\hline الدلالة & الارتباط & p \\
\hline$\overline{0.05}$ & 0.625 & -1 \\
\hline 0.01 & 0.782 & -2 \\
\hline $\begin{array}{c}0.01 \\
\end{array}$ & 0.701 & -3 \\
\hline 0.01 & 0.914 & -4 \\
\hline 0.01 & 0.840 & -5 \\
\hline
\end{tabular}

من خلال الجدول السابق نجد أن معاملات الارتباط كلها دالة عند مستوى (0.01 - 0.05) لاقترابها من الواحد

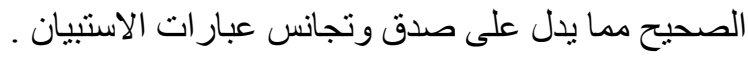

الصدق باستخدام الاتساق الااخلي بين الدرجة الكلية لكل محور والدرجة الكلية للاستبيان :

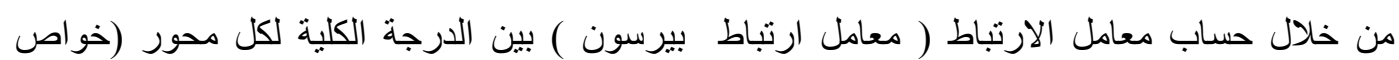

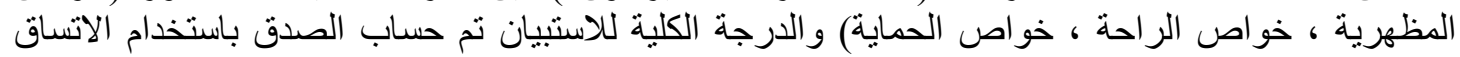

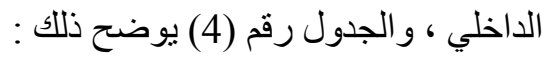




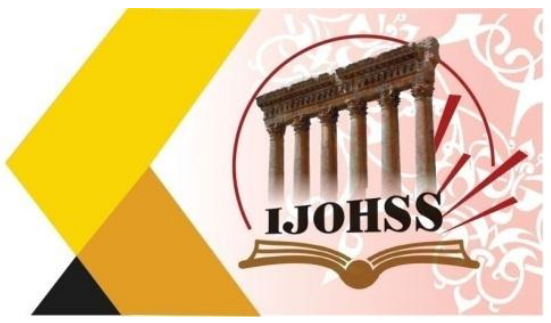

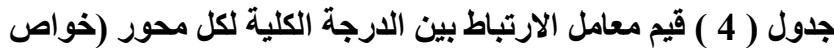

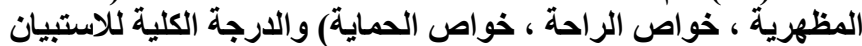

\begin{tabular}{|c|c|c|}
\hline الدالة الدالة & الارتباط & \\
\hline 0.01 & 0.864 & المحور الأول : خواص المظهرية \\
\hline 0.01 & 0.745 & المحور الثاني : خواص الراحة \\
\hline 0.01 & 0.812 & المحور الثالث : خواص الحماية \\
\hline
\end{tabular}

الجدول السابق يوضح أن نتائج معامل الارتباط كلها ذات دلالة احصائية عند مستوى (0.01) لاقتر ابها من

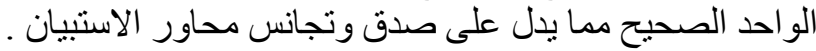

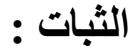

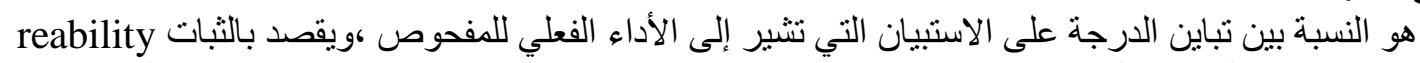

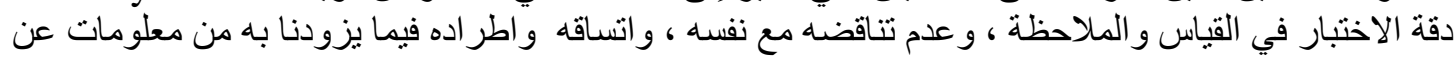

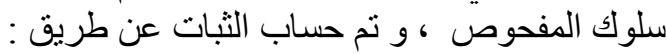

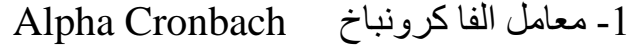
Split-half طريقة التجزئة النصفية

جدول ( 5 ) قيم معامل الثبات لمحاور استبيان العمال

\begin{tabular}{|c|c|c|}
\hline التجزئة النصفية & معامل الفا & المحاور \\
\hline $0.861-0.777$ & 0.823 & المحور الأول : خواص المظهرية \\
\hline $0.942-0.851$ & 0.904 & المحور الثاني : خواص الراحة \\
\hline $0.808-0.712$ & 0.769 & المحور الثالث : خواص الحماية \\
\hline $0.927-0.831$ & 0.885 & ثبات استبيان العمال ككل \\
\hline
\end{tabular}

الجدول السابق يوضح أن جميع قيم معامل الثبات : معامل الفا ، التجزئة النصفية دالة عند مستوى 0.01 مما يدل

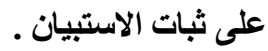

$$
\text { النتائج }
$$

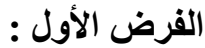

توجد فروق ذات دلالة إحصائية بين العشر تصاميم المقترحة في خو اص المظهرية وفقا لأراء العمال

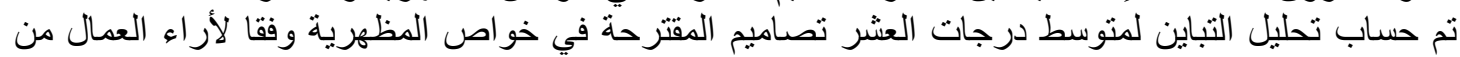

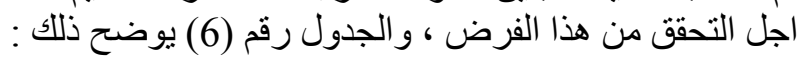

\begin{tabular}{c|c|c|c|c|c}
\multicolumn{7}{c}{} \\
\hline \\
\hline
\end{tabular}


المجلة المولية اللملوم الآنسانية والامتماعية International Journal on Humanities and Social Sciences website:www.ijohss.com Email:editor@ijohss.com العدد (30) فبراير 2022 ISSN: 2415 - 4822 Volume (30) February 2022

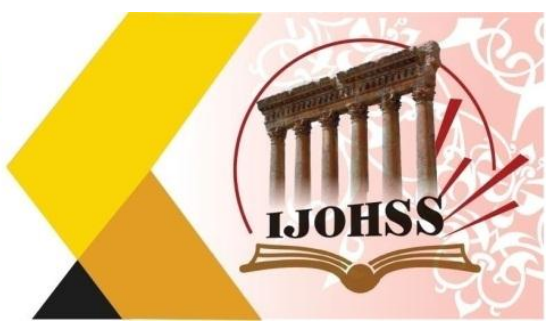

يتضح من الجدول السابق إن قيمة (ف) كانت (61.147) وهى قيمة ذات دلالة إحصائيا عند مستوى (0.01) ، ولمقال

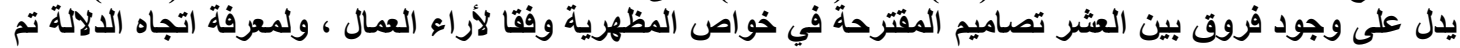
تطبيق اختبار LSD للمقارنات المتعددة ، والجدول التالي يوضح ذئل فئل :

جدول ( 7 ) اختبار LSD للمقارنات المتعددة

\begin{tabular}{|c|c|c|c|c|c|c|c|c|c|c|}
\hline 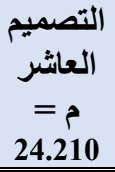 & $\begin{array}{c}\text { التصميع } \\
=1 \\
\text { التاسع } \\
29.260\end{array}$ & التصامن & $\begin{array}{c}\text { التصسيع } \\
=\text { التصابع } \\
33.286 \\
\end{array}$ & 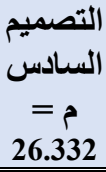 & التخمسيم & التصبيم & التصالثيث & التصاني & الأصميث & خواص المظ \\
\hline & & & & & & & & & - & التصميم الأول \\
\hline & & & & & & & & - & $* * 10.550$ & التصميم الثاني \\
\hline & & & & & & & - & $* 2.373$ & $* * 12.923$ & التصميم الثالث \\
\hline & & & & & & - & $* * 10.300$ & $* * 7.926$ & $* 2.623$ & التصميم الرابع \\
\hline & & & & & - & $* 2.336$ & $* * 7.963$ & $* * 5.590$ & $* * 4.960$ & التصميم الخامس \\
\hline & & & & - & $* * 18.547$ & $* * \mathbf{2 0 . 8 8 4}$ & $* * 10.584$ & $* * 12.957$ & $* * 23.507$ & التصميم السادس \\
\hline & & & - & $* * 6.954$ & $* * 11.593$ & $* * 13.930$ & $* * 3.630$ & $* * 6.003$ & $* * 16.553$ & التصميم السابع \\
\hline & & - & $* * 8.666$ & $* * 15.620$ & $* 2.926$ & $* * 5.263$ & $* * 5.036$ & $* 2.663$ & $* * 7.886$ & التصميم الثامن \\
\hline & - & $* * 12.693$ & $* * 4.026$ & *2.927 & $* * 15.620$ & $* * 17.956$ & $* * 7.656$ & $* * 10.030$ & $* * 20.580$ & التصميم التاسع \\
\hline- & $* * 5.050$ & $* * 17.743$ & $* * 9.076$ & $* 2.122$ & $* * 20.670$ & $* * 23.006$ & $* * 12.706$ & $* * 15.080$ & $* * 25.630$ & التصميم العاثر \\
\hline
\end{tabular}

$$
\text { خواص المظهرية }
$$

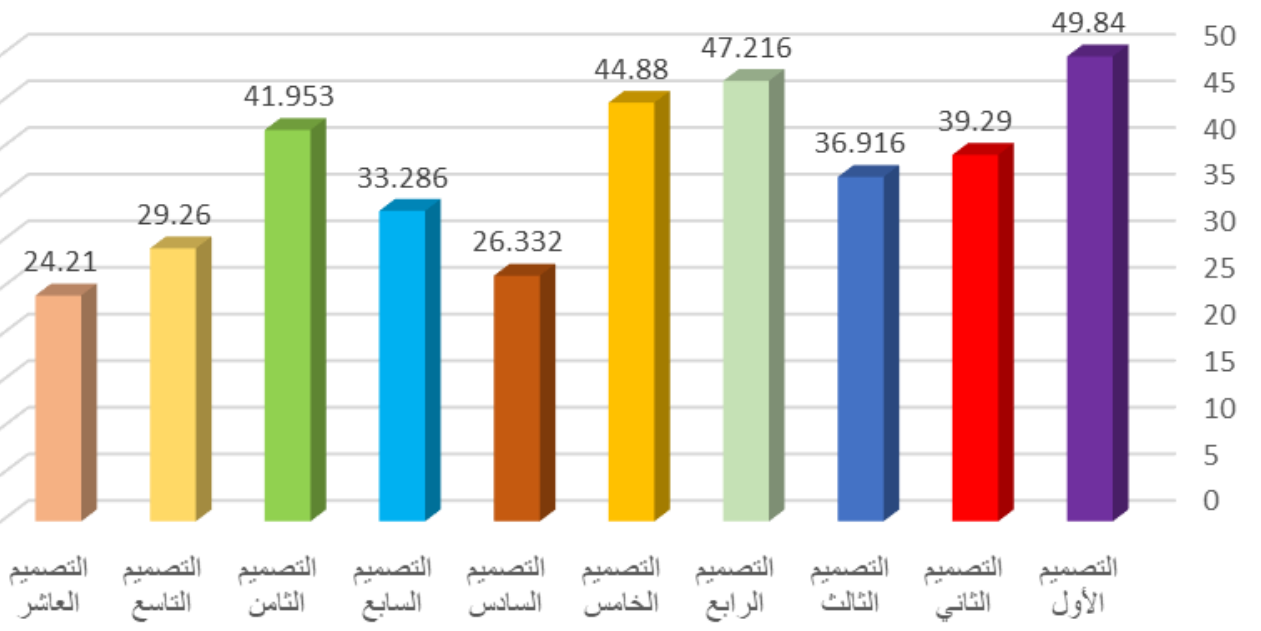

شكل ( 1 ) يوضح متوسط درجات العثر تصاميم المقترحة في خواص المظهرية وفقا لأراء العمال من خلال الجدول رقم ( 7 ) وايضا الشكل رقم ( 1 ) يتضح أن :

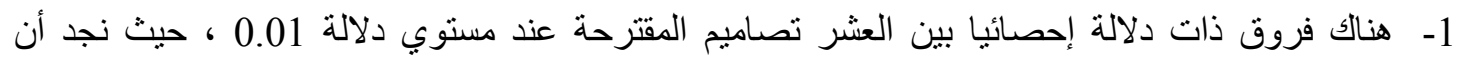
التصميم رقم "1" جاء كأفضل التصميمات في خو اصل المظهرية وفقا لأر اء العمال ، ثم يليه التصميم رقم "4" ، 


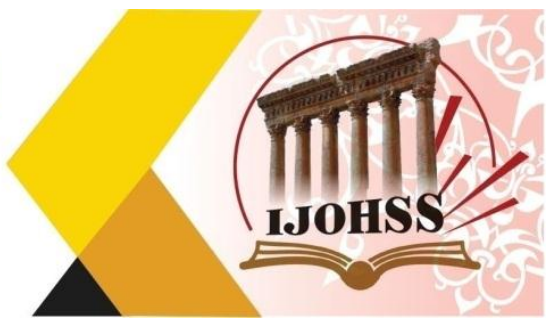

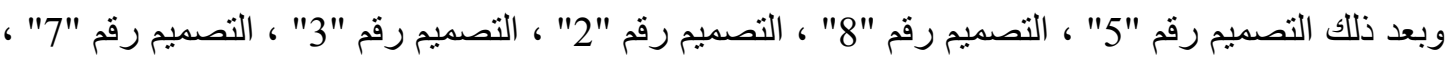

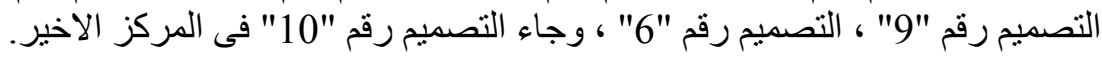

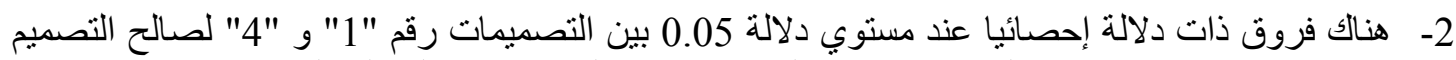

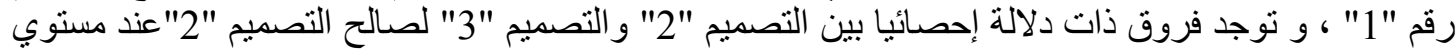
دلالة 0.05 ، كما توجد فروق ذات دات دلالة إحصائيا عند مستوب دلائلة

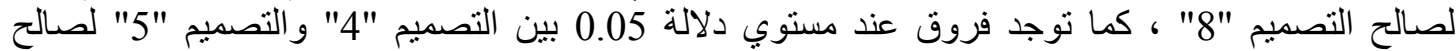

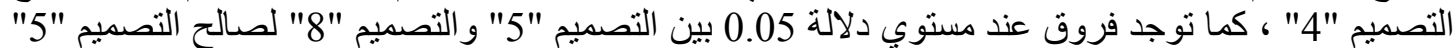

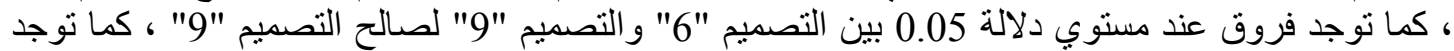

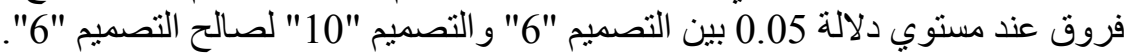

$$
\text { الفرض الثاني : }
$$

توجد فروق ذات دلالة إحصائية بين العشر تصاميم المقترحة في خو اص الر الراحة وفقا لأراء العمال

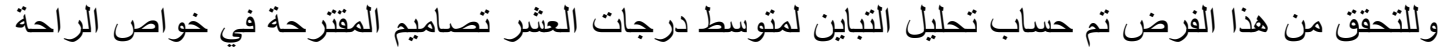

$$
\text { وفقا لأر اء العمال ، و الجدول التالي يوضح ذلك : }
$$

جدول ( 8 ) تحليل التباين لمتوسط درجات التصميمات

\begin{tabular}{|c|c|c|c|c|c|}
\hline الدلالة & قيمة (ف) & الحربية & متوسط المربعات & مجموع المربعات & خواص الراحة \\
\hline \multirow{3}{*}{0.01} & \multirow{2}{*}{50.701} & 9 & 40 & 41778.086 & بين المجموعات \\
\hline & & 590 & 91.557 & 54018.788 & داخل المجموعات \\
\hline & & 599 & & 95796.874 & المجموع \\
\hline
\end{tabular}
العشر المقترحة في خواص الثراحة وفقا لأراء العمال

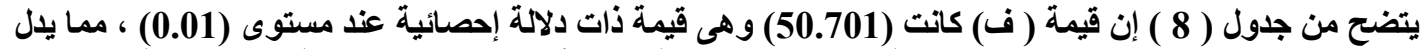

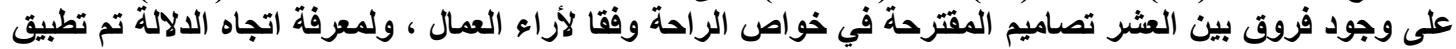

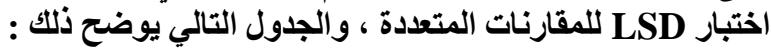

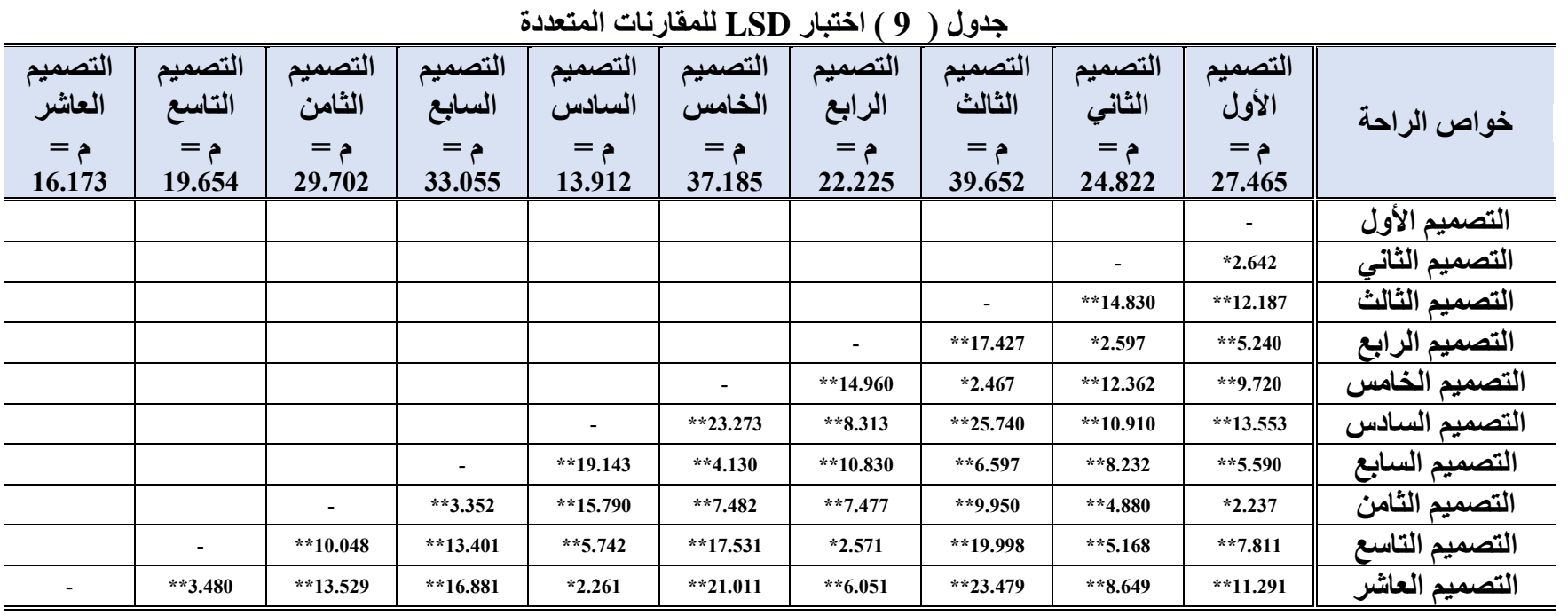


العدد (30) فبراير 2022

Volume (30) February 2022

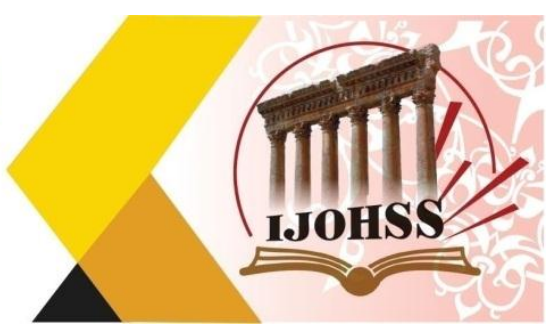

ISSN: $2415-4822$

$$
\text { خواص الراحة }
$$

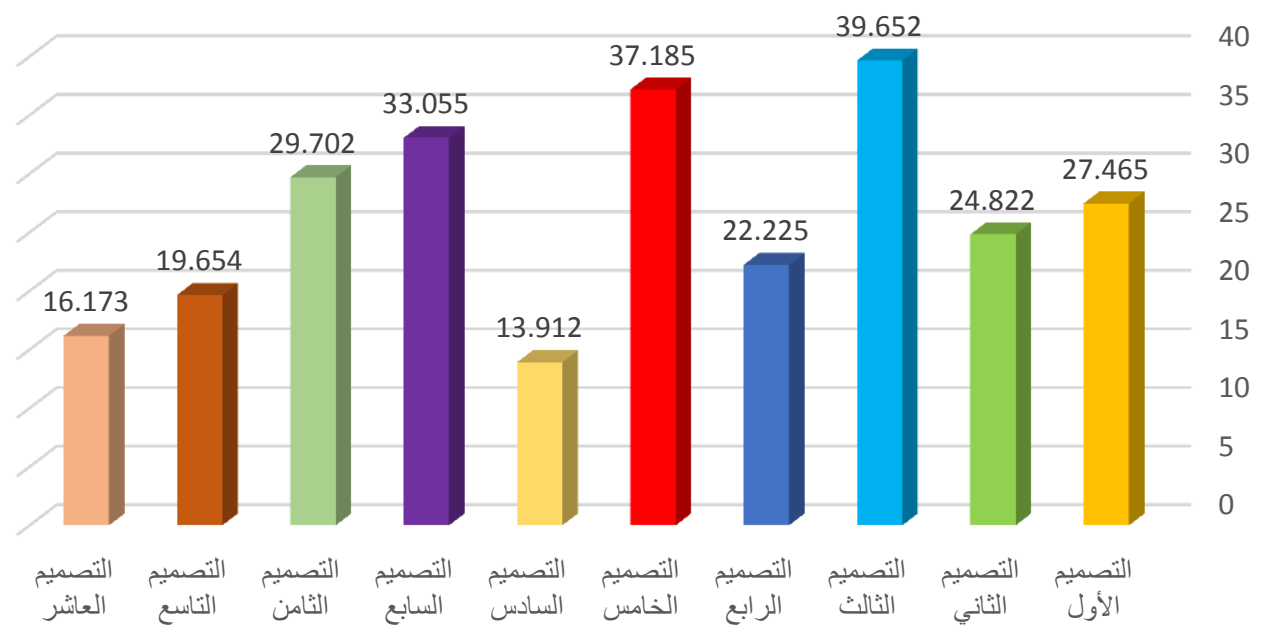

شكل ( 2 ) يوضح متوسط درجات العشر تصاميم المقترحة في خواص الراحة وفقا لأراء العمال

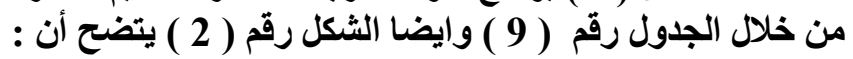

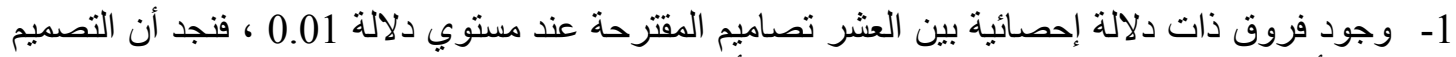

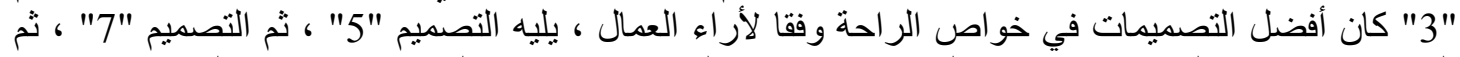

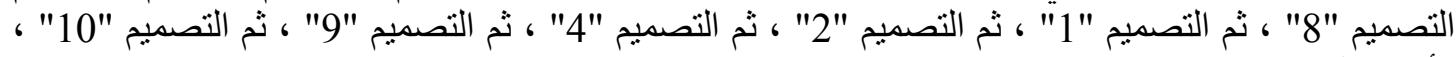

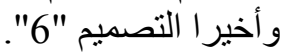

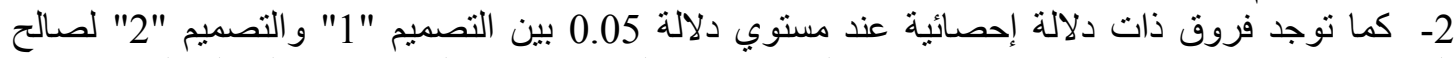

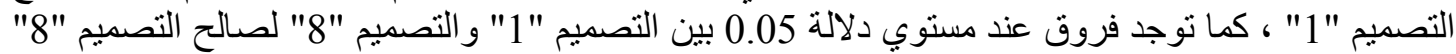

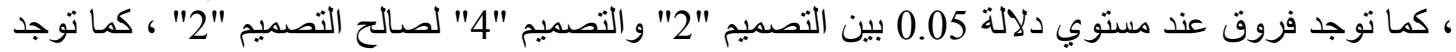

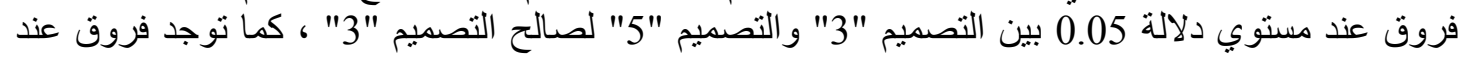

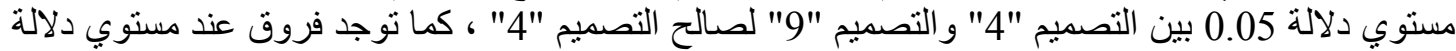

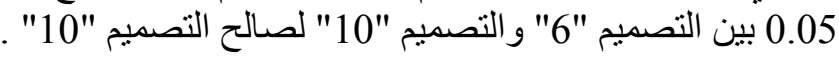

الفرض الثالث :

توجد فروق ذات دلالة إحصائية بين العشر تصاميم المقترحة في خو اص الحماية وفقا لأر اء العمال

وللتحقق من هذا الفرض تم حساب تحليل التباين لمنوسط درجات العشر تصاميم المقترحة في خو اص الحماية وفقا لأر اء العمال ، و الجدول التنالي يوضح ذلت :

جدول ( 10 ) تحليل التباين لمتوسط درجات التصميمات

\begin{tabular}{|c|c|c|c|c|c|}
\hline الدلالة & قيمة (ف) & الرجية & متوسط المربعات & مجموع المربعات & خواص الحماية \\
\hline \multirow{3}{*}{0.0101} & \multirow{2}{*}{31.476} & 9 & 20010.808 & 180097.271 & بين المجموعات \\
\hline & & 590 & 635.746 & 375089.970 & داخل المجموعات \\
\hline & & 599 & & $\begin{array}{c}555187.241 \\
\end{array}$ & المجموع \\
\hline
\end{tabular}
العثر المقترحة في خواص الحماية وفقا لأراء العمال 
المجلة المولية اللملوم الآنسانية والامتماعية International Journal on Humanities and Social Sciences website:www.ijohss.com Email:editor@ijohss.com العدد (30) فبراير 2022 ISSN: $2415-4822$ Volume (30) February 2022

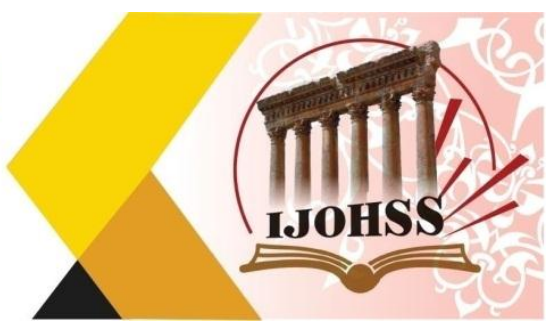

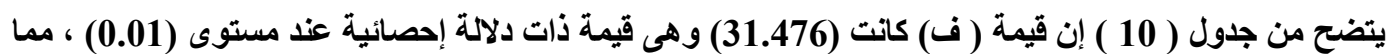

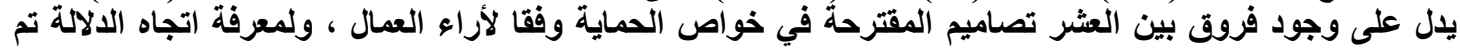
تطبيق اختبار LSD للمقارنات المتعددة ، والجدول التالي يوضح ذئر ذلك :

جدول ( 11 ) اختبار LSD للمقارنات المتعددة

\begin{tabular}{|c|c|c|c|c|c|c|c|c|c|c|}
\hline التصاشريم & $\begin{array}{c}\text { التصمبع } \\
=\text { التاسع } \\
\text { التصع } \\
12.070\end{array}$ & $\begin{array}{c}\text { التصامن } \\
\text { التصميم } \\
\text { الثام } 15.978 \\
\end{array}$ & $\begin{array}{c}\text { التصابع } \\
=\text { التصبع } \\
\text { السبع } \\
18.674\end{array}$ & $\begin{array}{c}\text { التصادسيم } \\
=\text { التصاد } \\
13.956\end{array}$ & $\begin{array}{c}\text { التصميم } \\
=\text { التصس } \\
5.227 \\
\end{array}$ & $\begin{array}{c}\text { التصميع } \\
\text { الترابع } \\
\text { 22.737 } \\
\text { 22. }\end{array}$ & $\begin{array}{c}\text { التصميث } \\
=\text { التصاث } \\
\text { 24.625 } \\
\end{array}$ & $\begin{array}{c}\text { التصميم } \\
\text { الثاني } \\
=6.708 \\
6\end{array}$ & $\begin{array}{c}\text { التصميم } \\
=\text { الأول } \\
9.489 \\
0\end{array}$ & خواص الحماية \\
\hline & & & & & & & & & - & التصميم الأول \\
\hline & & & & & & & & - & $* 2.781$ & التصميم الثانى \\
\hline & & & & & & & - & $* * 17.916$ & $* * 15.135$ & التصميم الثالث \\
\hline & & & & & - & $* * 17.510$ & $* * 19.398$ & 1.481 & $* * 4.262$ & التصميم الخامس \\
\hline & & & & - & $* * 8.729$ & $* * 8.781$ & $* * 10.669$ & $* * 7.247$ & $* * 4.466$ & التصميم السادس \\
\hline & & & - & $* * 4.718$ & $* * 13.447$ & $* * 4.063$ & $* * 5.951$ & $* * 11.965$ & $* * 9.184$ & التصميم السابع \\
\hline & & - & *2.696 & *2.022 & $* * 10.751$ & $* * 6.759$ & $* * 8.647$ & $* * 9.269$ & $* * 6.488$ & التصميم الثامن \\
\hline & - & $* * 3.908$ & $* * 6.604$ & 1.886 & $* * 6.843$ & $* * 10.667$ & $* * 12.555$ & $* * 5.361$ & $* 2.580$ & التصميم التاسع \\
\hline - & *2.187 & $* * 6.095$ & $* * 8.791$ & $* * 4.073$ & $* * 4.655$ & $* * 12.855$ & **14.742 & $* * 3.174$ & 0.363 & التصميم العاشر \\
\hline
\end{tabular}

$$
\text { خو اص الحماية }
$$

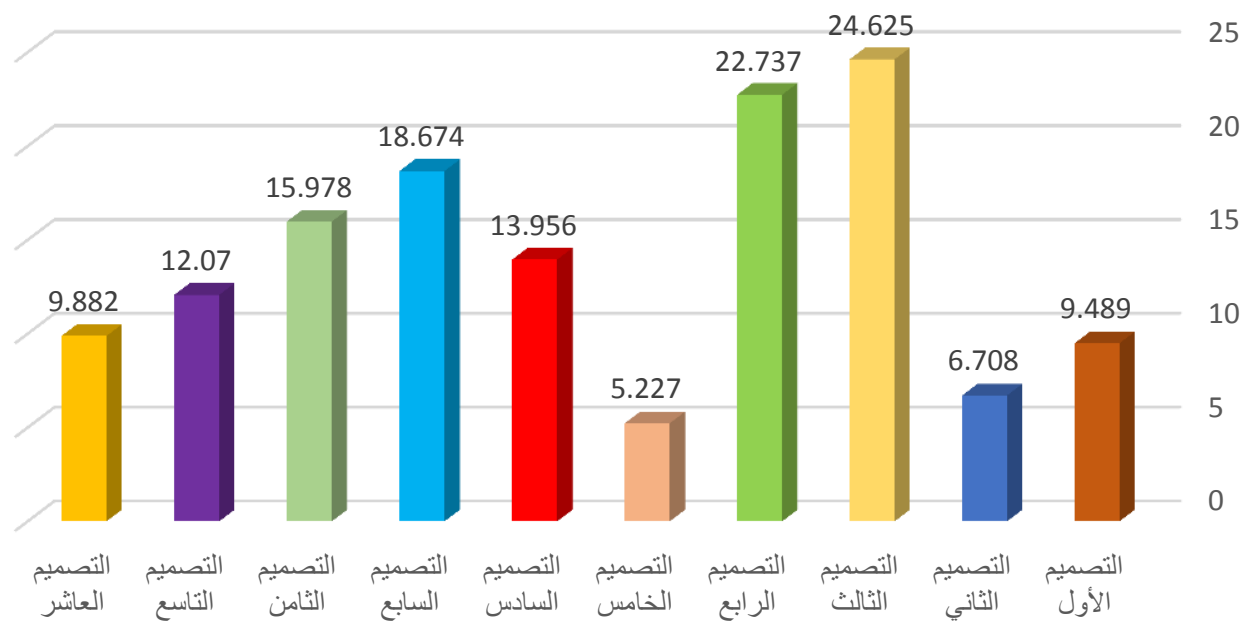

شكل ( 3 ) يوضح متوسط درجات العشر تصاميم المقترحة في خواص الحماية وفقا لأراء العمال

من خلال الجدول رقم ( 11 ) وايضا الثكل رقم ( 3 ) ) يتضح أن :

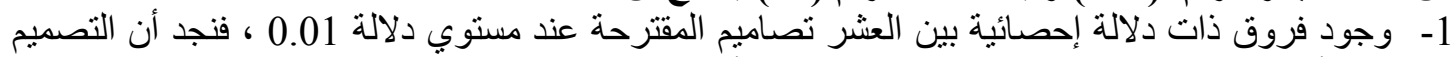

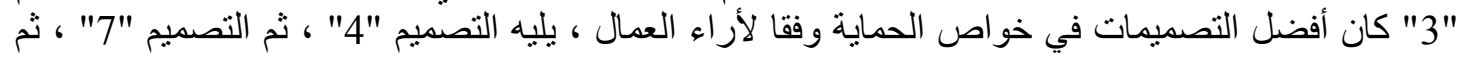

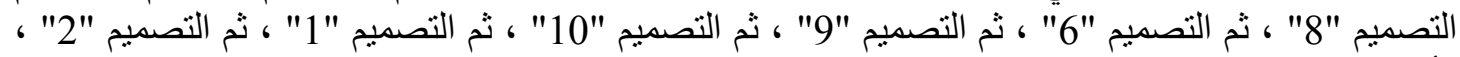

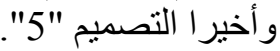




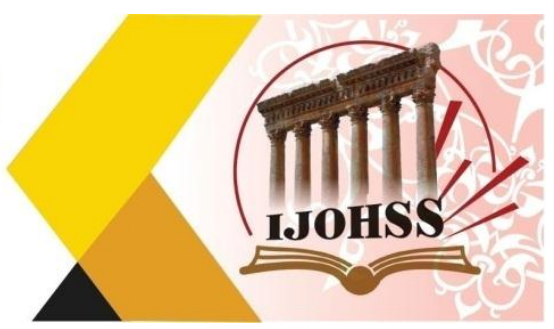

2- كما توجد فروق عند مستوي دلالة 0.05 بين التصميم "1" و التصميم "2" لصالح التصميم "1" ، كما توجد

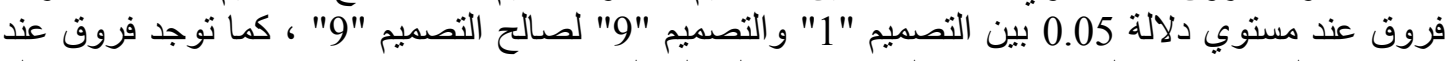

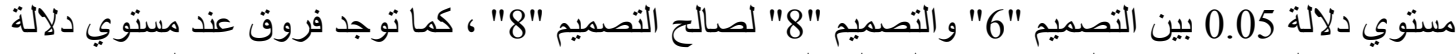

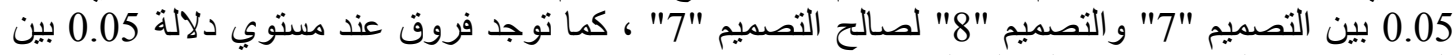

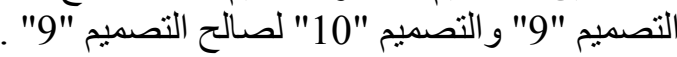

3- بينما لا توجد فروق بين التصميم "1" و التصميم "10" ، بينما لا توجد فروق بين التصميم "2" و و التصميم

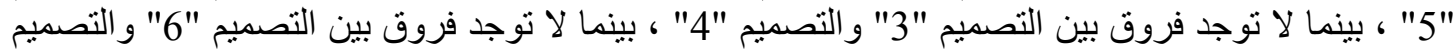
. "9"

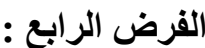

توجد فروق ذات دلالة إحصائية بين العشر تصاميم المقترحة وفقا لأر اء العمال

وللتحقق من هذا الفرض تم حساب تحليل التباين لمتوسط درجات العشر تصاميم المقترحة وفقا لأر اء العمال ، و الجدول التالي يوضح ذذان اللك :

جدول ( 12 ) تحليل التباين لمتوسط درجات العشر تصاميم المقترحة وفقا لأراء العمال

\begin{tabular}{|c|c|c|c|c|c|}
\hline الدلالة & قيمة (ف) & الرجات & متوسط المربعات & مجموع المربعات & المجموع الكلي "العمال" \\
\hline \multirow{3}{*}{0.01} & \multirow{2}{*}{44.740} & 9 & 5629.534 & $\begin{array}{l}50665.808 \\
\end{array}$ & بين المجموعات \\
\hline & & 590 & 125.828 & 74238.719 & داخل المجموعات \\
\hline & & 599 & & 124904.527 & المجموع \\
\hline
\end{tabular}

يتضح من جدول ( 12 ) إن قيمة ( ف) كانت (44.740) و هى قيمة ذات دلالة إحصائية عند مستوى (0.01) ، مما بدل على وجود فروق بين العشر تصاميم المقترحة وفقا لأر اء اء العمال ، ولمعرفة التجاه الداليالة تم تطبيق

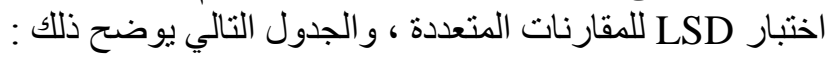

جدول ( 13 ) ) اختبار LSD للمقارنات المتعددة

\begin{tabular}{|c|c|c|c|c|c|c|c|c|c|c|}
\hline $\begin{array}{c}\text { التصميثر } \\
=\text { التصر } \\
50.265\end{array}$ & 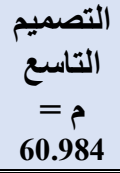 & التثامنيم & $\begin{array}{c}\text { التصميع } \\
=\text { السبع } \\
85.015\end{array}$ & التصادسبم & التصامسيث & $\begin{array}{c}\text { الترابع } \\
=0 \\
92.179\end{array}$ & الثالثمبم & التصميم & التصميث & "المجموع الاكلا \\
\hline & & & & & & & & & - & التصميم الأول \\
\hline & & & & & & & & - & $* * 15.972$ & التصميم الثاني \\
\hline & & & & & & & - & $* * 30.371$ & $* * 14.399$ & التصميم الثالث \\
\hline & & & & & & - & $* * 9.015$ & $* * 21.356$ & $* * 5.384$ & التصميم الرابع \\
\hline & & & & & - & $* * 4.887$ & $* * 13.902$ & $* * 16.469$ & 0.496 & التصميم الخامس \\
\hline & & & & - & $* * 33.091$ & $* * 37.978$ & $* * 46.993$ & $* * 16.622$ & $* * 32.594$ & التصميم السادس \\
\hline & & & - & $* * 30.815$ & $* 2.276$ & $* * 7.163$ & $* * 16.178$ & $* * 14.193$ & 1.779 & التصميم السابع \\
\hline & & - & *2.618 & $* * 33.433$ & 0.342 & $* * 4.545$ & $* * 13.560$ & $* * 16.811$ & 0.838 & التصميم الثامن \\
\hline & - & $* * 26.649$ & $* * \mathbf{2 4 . 0 3 1}$ & $* * 6.783$ & $* * 26.307$ & $* * 31.195$ & $* * 40.210$ & $* * 9.838$ & $* * 25.811$ & التصميم التاسع \\
\hline
\end{tabular}



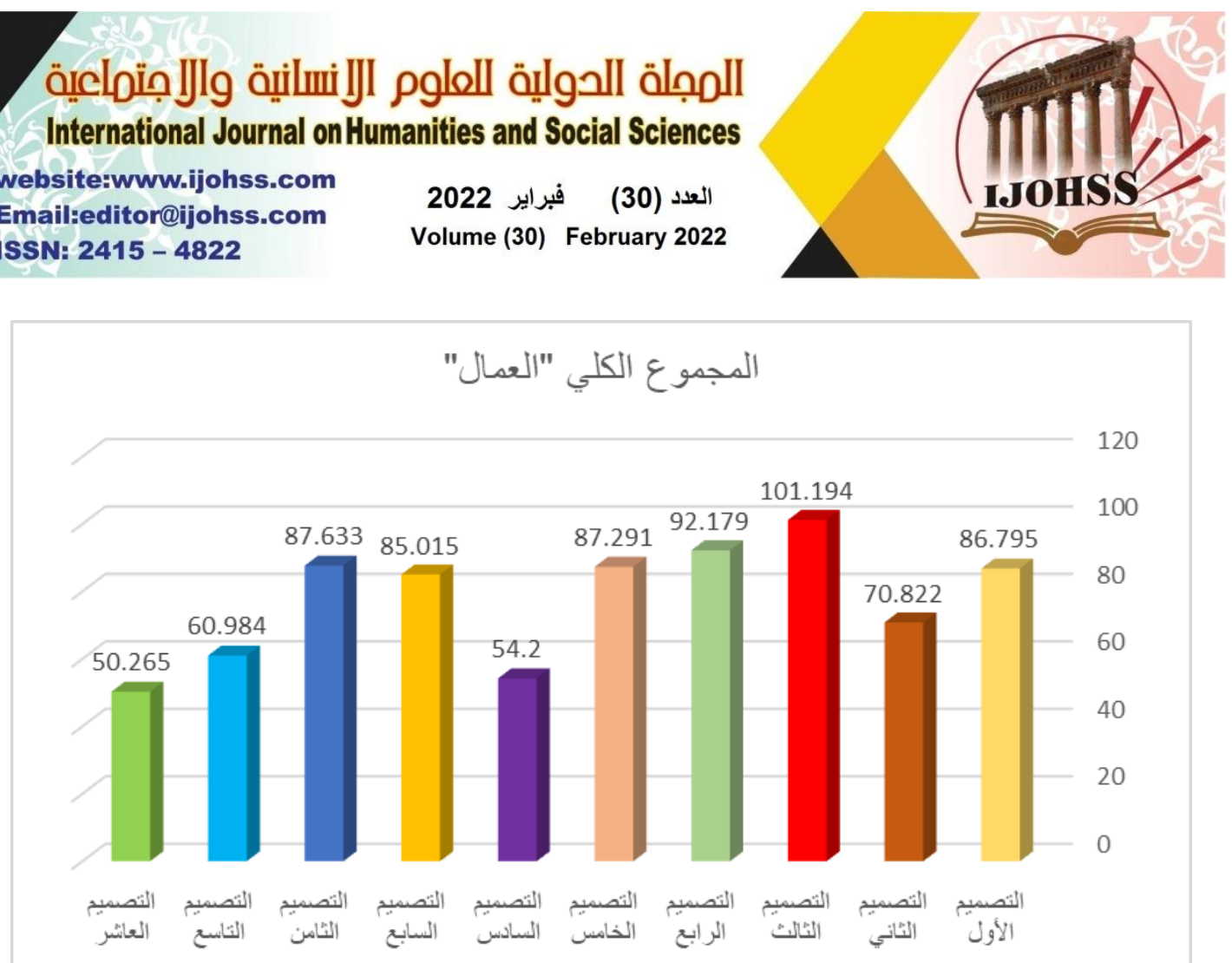

شكل ( ) يوضح متوسط درجات العشر تصاميم المقترحة وفقا لأراء العمال

$$
\text { من خلال الجدول رقم ( } 13 \text { ) وايضا الشكل رقم ( } 4 \text { ) يتضح أن : }
$$

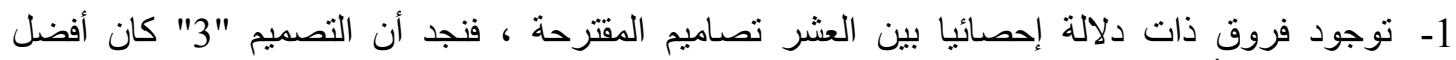

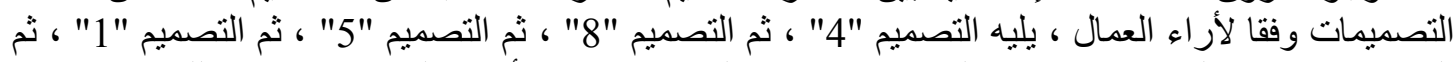
التصميم "7" ، ثم التصميم "2" ، ثم التصميم "9" ، ثم التصميم "6" ، ، و أخيرا التصميم "10" و وذلك عند مستوي

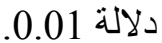

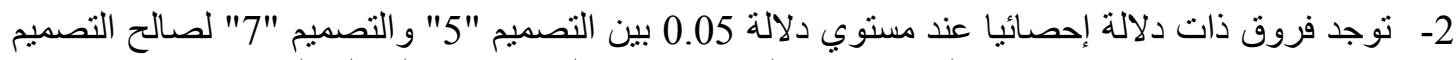

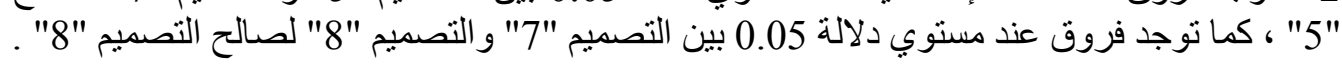

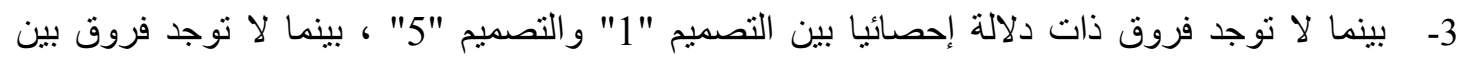

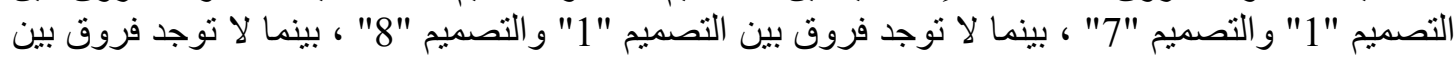

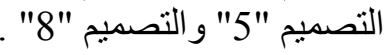
1التو العملت : على تطوير ملابس العمال في مختلف قطاعات الصناعة ، لتحقيق منطلبات الأداء الوظيفي والر احة

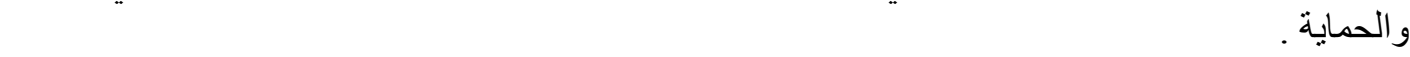

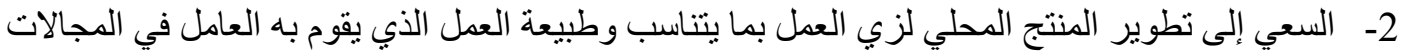

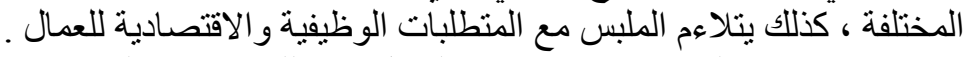
3- وضع معايير لتحقيق جودة ملابس العمال طبقا للمو اصفات القيات القياسية. 


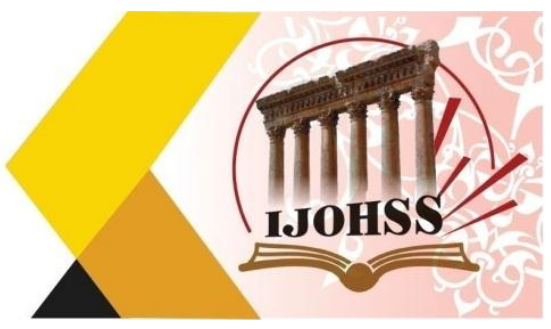

المراجع

1- السليماني ، نسرين فريد حمزة ( 2021 ) كفاءة كتاب الكتروني تفاعلي في تعلم تصميم الازياء الوظيفية ،

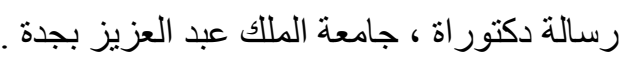

2- دبليو ، هو ارد رييس ( 2005م ) الاقشة و الملابس في الصحة و المرض ،ترجمة : قثقري ، خديجة روزي ، مر اجعة : محمد عبداله سعد ، جدة .

3- سلام ، عزة ( 2007 ) در اسة العو امل المؤثرة على العمليات الإنتاجية في مصانع الملابس الجاهزة في المملكة العربية السعودية ، مجلة الاقتصاد المنزلي ، جامعة المنوفية. 4- سماحة ، وفاء محمد ، ( 2017 ) تصميم الازياء - حياكة الملابس ومستلزماتها ، المملكة العربية السعودية ،

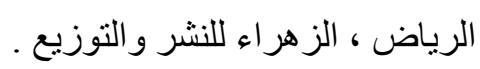
5- سالم ، شيرين صلاح الدين علي ( 2006) در اسة المنطلبات الوظيفية و التصميمية لملابس العمال، رسالة ماجستير ، كلية الفنون التطبيقية ، جامعة حلوان ، القاهرة

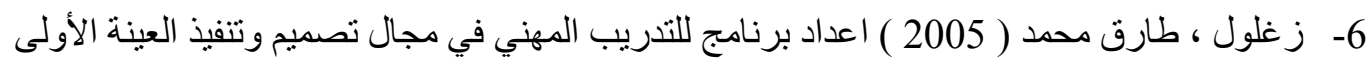

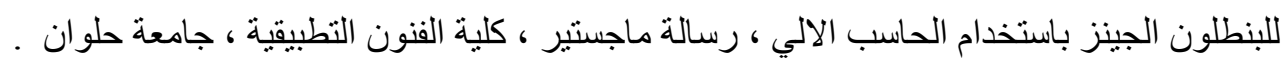

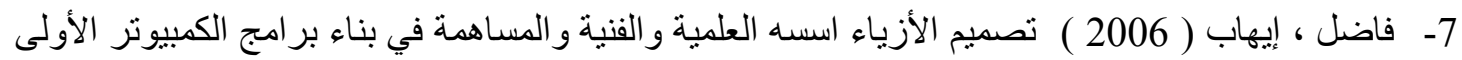
التطبيقية ، دار الكتاب الحديث ، القاهرة . ل

8- Hallgrimsson,Bjarki: prototyping and Modelmaking for product Design ,

Laurence King Publishing Limited : London , 2012.

9- Tomasine, S.( 2005) Chamistry\& Technology of Fabric Preparation \& Finishing, North Carolina state University .

10- Desall,A.A.( 2003) Clothing that offers protection against ultraviolet radiation,textile magazine. 